ISSN: 0213-2079 - ISSN electrónico: 2386-3889

DOI: https://doi.org/10.14201/shhmo2017392185219

\title{
LAS INFRAESTRUCTURAS PORTUARIAS DE LA BAHÍA DE CÁDIZ ANTE EL RETO DEL MONOPOLIO AMERICANO
}

\section{The Port Infrastructures of the Bay of Cadiz before the Challenge of the American Monopoly}

\author{
Juan José IGLESIAS RODRÍGUEZ \\ Universidad de Sevilla \\ Correo-e: jjiglesias@us.es
}

RESUMEN: El traslado de la Casa de la Contratación de Indias de Sevilla a Cádiz en 1717 se justificó por los problemas de navegabilidad del río Guadalquivir, que dificultaban la continuidad del monopolio sevillano. Frente a ello, la Bahía de Cádiz parecía adaptarse mucho mejor a las exigencias de la Carrera de Indias, al ofrecer un puerto más adecuado y funcional para las flotas. De hecho, la cabecera del tráfico colonial americano se había trasladado ya oficialmente a Cádiz en 1680. El traslado de las instituciones rectoras de la Carrera -la Casa de la Contratación y el Consulado de Cargadores-aparecía como la consecuencia lógica de este proceso de basculación de la capitalidad del monopolio americano. La pregunta que se plantea el presente trabajo es cuáles fueron las condiciones reales de navegabilidad que presentaba la Bahía en aquellos momentos y cómo se vieron modificadas por el nuevo rol que le tocó asumir. Al mismo tiempo, este trabajo se cuestiona cómo evolucionó el sistema portuario gaditano ante la nueva coyuntura atlántica, teniendo presente además que la Bahía de Cádiz no solo asumió la capital del monopolio americano, sino que también fue designada como uno de los tres departamentos marítimos que resultaron de la reorganización borbónica de la Armada. El intenso tráfico naval resultante, tanto de navíos mercantes como de guerra, introdujo cambios y planteó necesidades logísticas que demandaron eficaces respuestas. El objetivo de

Ediciones Universidad de Salamanca / @®@@ Stud. his., H. ${ }^{a}$ mod., 39, n. 2 (2017), pp. 185-219 
este trabajo es explorar estas interesantes cuestiones, sobre todo en lo que respecta al funcionamiento de la Carrera de Indias.

Palabras clave: Bahía de Cádiz; Carrera de Indias; navegación; infraestructuras portuarias; siglo XvIII.

ABSTRACT: The transfer of the Casa de la Contratación from Seville to Cadiz in 1717 was justified by the navigability problems of the Guadalquivir river, which hindered the continuity of the Sevillian monopoly. Faced with this, the Bay of Cadiz seemed to be much better suited to the demands of the Carrera de Indias, by offering a more suitable and functional port for the fleets. In fact, the head of American colonial traffic had already been officially transferred to Cadiz in 1680 . The transfer of the governing institutions of the Carrera -the Casa de la Contratacion and the Consulado de Cargadores-appeared as the logical consequence in this process of tilting of the capital of the American monopoly. The question that addresses this paper is what were the real conditions of navigability that presented the Bay of Cadiz in those moments and how they were modified by the new role that had to assume to him. At the same time, this paper examines how the Cadiz port system evolved face of the new Atlantic situation, bearing in mind that the Bay of Cadiz not only assumed the capital of the American monopoly, but was also designated as one of the three maritime departments that resulted from the Bourbon reorganization of the Navy. The resulting intense naval traffic, both merchant ships and war ships, introduced changes and raised logistical needs that demanded effective responses. The purpose of this paper is to explore these interesting issues, especially in regard to the running of the Carrera de Indias.

Key words: Bay of Cadiz; Carrera de Indias; Navigation, Port Infrastructures, $18^{\text {th }}$ Century.

\section{INTRODUCCIÓN}

La historiografía sobre la Carrera de Indias ha prestado, en general, poca atención a las infraestructuras portuarias que soportaron el tráfico naval entre España y América. La cuestión entraña su lógica, en la medida de que, al lado de lo que significó la Carrera en términos navales, económicos y humanos, la situación de los puertos no deja de percibirse como una cuestión meramente subsidiaria. La gran organización jurídico-técnica del sistema, las complejas aritméticas del 
tráfico mercantil americano y las rutilantes cifras del metal precioso arribado de las colonias han atraído comprensiblemente mucho más la atención de los historiadores que la realidad del operativo portuario que permitió la navegación a Indias. La ausencia de estudios sobre las condiciones de los puertos de la Carrera es probablemente mayor por lo que respecta a Cádiz. La problemática asociada a la navegación por el río Guadalquivir y los naufragios provocados por la barra de este mismo río en su desembocadura por Sanlúcar de Barrameda son algo más conocidos. Sin embargo, de Cádiz es muy poco lo que se ha escrito. Pierre Chaunu se detuvo lo justo en este aspecto para señalar algunas cuestiones, como el hecho de que Cádiz contaba con un puerto cómodo, bien conectado por mar pero mal por tierra, que disponía de pocos espacios para almacenes y que su posición estaba muy expuesta a ataques enemigos. De los puertos de la Bahía, el mismo autor afirmó que, enclavados entre arenas y marismas, se degradaban con rapidez, mientras que los medios técnicos de la época impedían su mantenimiento ${ }^{1}$. Cuando Antonio García-Baquero consagró una parte de su Cádiz y el Atlántico a la infraestructura material del tráfico americano, atendió a los vehículos del comercio, es decir, los barcos, a las rutas que surcaron y a las tripulaciones que los manejaron, pero no al sistema portuario ${ }^{2}$. Algo más explícito al respecto es Manuel Bustos, quien dedica algunas páginas al complejo mercantil-portuario de Cádiz y su bahía en su obra sobre Cádiz en el sistema atlántico ${ }^{3}$. A partir de aquí, los trabajos consagrados a la cuestión no son muchos. José Quintero se ha ocupado específicamente en diversos y muy meritorios trabajos de la Carraca como arsenal naval de la Armada ${ }^{4}$. Juan Torrejón, por su parte, ha trazado una síntesis general de la evolución histórica del puerto de Cádiz, con interesantes noticias sobre el siglo XviII ${ }^{5}$. Lourdes Márquez y Carlos Alonso han realizado también algunas aportaciones de interés, a partir sobre todo del análisis de la cartografía histórica ${ }^{6}$. El autor de estas líneas, finalmente, ha publicado algunos trabajos sobre

1. Chaunu, P.: Sevilla y América, siglos Xvi y Xvir. Sevilla, 1983, pp. 35-40.

2. García-Baquero González, A.: Cádiz y el Atlántico (1717-1778). El comercio colonial español bajo el monopolio gaditano. Cádiz, 1988, tomo I, pp. 225-302.

3. Bustos Rodríguez, M.: Cádiz en el sistema atlántico. La ciudad, sus comerciantes y la actividad mercantil (1650-1830). Madrid, 2005, pp. 80-90.

4. Quintero González, J.: El arsenal de la Carraca (1717-1736). Madrid, 2000; La Carraca: el primer arsenal ilustrado español (1717-1776). Madrid, 2005.

5. Torrejón Chaves, J.: «El área portuaria de la Bahía de Cádiz: tres mil años de puerto», en Puertos españoles en la Historia. Madrid, 1994, pp. 117-145.

6. Márquez Carmona. L.: «El sistema portuario de la Bahía de Cádiz durante el siglo XviII», Revista de Historia de El Puerto, 36, 2006, pp. 11-47; Márquez Carmona, L. y Alonso Villalobos, C.: «El sistema portuario de la bahía de Cádiz en época moderna a través de la cartografía histórica», en García Hurtado, M.-R. y Rey Castelao, O.: Fronteras de agua:

Ediciones Universidad de Salamanca / @®@@ Stud. his., H. ${ }^{a}$ mod., 39, n. 2 (2017), pp. 185-219 
la temática, que se han centrado fundamentalmente en el papel jugado por el caño del Trocadero en la logística de la Carrera de Indias.

El traslado de la cabecera de flotas y el posterior de la Casa de la Contratación de Sevilla a Cádiz se justificó en buena medida por razones técnicas de navegación ${ }^{8}$. A las dificultades que entrañaban los bajos y meandros del Guadalquivir para el paso de unos buques de creciente calado se oponía la amplitud y espaciosidad de la Bahía gaditana, mucho más cómoda y adaptada para acoger las flotas que el río de Sevilla. Esto no pasó de ser, sin embargo, un mero artificio argumental. Lo cierto es que desde tiempo atrás los barcos de la Carrera cargaban y descargaban en buena medida en la bahía gaditana, y que desde 1680 Cádiz había reemplazado a Sevilla como cabecera de las flotas. En realidad, las razones del traslado de la Casa de la Contratación a Cádiz era muy otras. Las preferencias de los comerciantes extranjeros, que habían trasladado su base de operaciones a la Bahía; las mayores posibilidades que ofrecía esta al fraude, al tratarse de una espacio más abierto que complicaba el control del tráfico; las rebajas fiscales que ofrecía Cádiz ${ }^{9}$, y, finalmente, los generosos servicios que ofreció esta ciudad y que predispusieron el ánimo de los gobernantes a su favor se han citado como causas de una decisión política que fue determinante en la historia del monopolio americano ${ }^{10}$. A todo este conjunto de causas hay que añadir que, en el nuevo diseño de la política naval de la Corona, Cádiz pasaría a jugar un papel fundamental como sede de uno de los tres departamentos marítimos concebidos por el gobierno, por cuya causa la Bahía obtendría un especial protagonismo en la política atlántica española.

La basculación hacia Cádiz de la capitalidad del tráfico colonial americano a lo largo del proceso histórico que culmina con el traslado de la Casa de la Contratación y del Consulado de Cargadores a Indias en 1717 significa la consagración

las ciudades portuarias y su universo cultural (siglos XVI-XXI). Santiago de Compostela, 2016, pp. 181-195.

7. Iglesias Rodríguez, J.-J.: «El Trocadero en la política atlántica durante los siglos modernos», en Álvarez Santaló, L.-C. (coord.): Estudios de Historia Moderna en homenaje al profesor Antonio García-Baquero. Sevilla, 2009, pp. 141-158; «El 'canal prodigioso': el caño del Trocadero en el siglo xviII», Matagorda, 1, 2015, pp. 47-77; «El complejo portuario gaditano en el siglo XviII», e-Spania. Revue interdisciplinaire d'études hispaniques médiévales et modernes, 25, oct. 2016 [en línea], https://e-spania.revues.org/25989.

8. Véase, en este mismo informe, el trabajo de Tapias Herrero, E.: «Aspectos navales en el traslado de la Casa de Contratación».

9. García-Baquero González, A.: «Los 'tratos y contratos' del capital comercial gaditano: la compra en empeño a la corona, en 1655, de las alcabalas de la ciudad, su término y bahía», en Comercio y burguesía mercantil en el Cádiz de la Carrera de Indias. Cádiz, 1991, pp. 36-65.

10. García-Baquero González, A.: Cádiz y el Atlántico, op. cit., t. I, pp. 104-109. 
de esta ciudad como el principal referente en la jerarquía portuaria española hasta comienzos del siglo XIX ${ }^{11}$, pero plantea algunas cuestiones desde el específico ángulo de análisis que asume el presente trabajo: ¿con qué infraestructuras portuarias contaba Cádiz para asumir esta responsabilidad y qué adaptaciones forzaron en ellas las nuevas circunstancias?, ¿qué condiciones de navegabilidad ofrecía la Bahía de Cádiz al comercio colonial y cómo se vieron estas afectadas por el cambio de sede del monopolio?, ¿qué respuesta ofrecieron los comerciantes y navieros gaditanos a las necesidades de mantenimiento de los buques de la Carrera? Estas preguntas -entre otras de similar índole- requieren respuestas convincentes a la hora de llevar a cabo una reconstrucción lo más integral posible del funcionamiento de la Carrera de Indias en el siglo xviII. El objetivo de este trabajo es adelantar algunas de esas respuestas, aunque con un carácter provisional, aprovechando para ello fundamentalmente las posibilidades que ofrece la documentación municipal gaditana y la conservada en el Archivo General de Indias. Futuras investigaciones deberán completar la visión que se desprende de los citados fondos.

\section{EL PUERTO DE LA CIUDAD}

\subsection{Primeras actuaciones de urgencia}

A comienzos del mismo año 1717 se llevaron ya a cabo trabajos de reparación del muelle gaditano. La iniciativa la impulsó el gobernador de la ciudad, a la vista de los desperfectos que presentaba esta vital infraestructura y la ruina que amenazaba. El cabildo se enfrentaba a la carencia de fondos para afrontar este gasto y a lo perentorio de las obras, por lo que uno de los diputados nombrados para llevarlas a efecto, Felipe de Barrios, debió adelantar de su propio peculio la cantidad de 3.500 reales para atender a las actuaciones más urgentes. Sin embargo, según los alarifes de la ciudad, eran precisos seis mil reales más para pagar los reparos. El cabildo acordó que tanto la cantidad ya empleada como las que quedasen por gastar se sacaran del arbitrio de la obra del arrecife de la Isla de León, hasta tanto el Consejo de Castilla no señalase otro medio más oportuno. El acuerdo no fue completamente unánime, suscitando alguna resistencia entre los capitulares ${ }^{12}$.

11. SAupIN, G.: «Mondialisation et modification des hiérarchies des grands ports de commerce, mi xvire - mi xixe siècle: une comparaison entre l'Espagne, la France et la Grande Bretagne», Nuevo Mundo. Mundos Nuevos [en línea], Colloques, puesto en línea el 16 de diciembre de 2016, consultado el 19 de mayo de 2017. http://nuevomundo.revues.org/69920.

12. Archivo Histórico Municipal de Cádiz [en adelante AHMC], Libros de Actas Capitulares [en adelante LAC], año 1717, cabildo de 14 de enero, fols. 17-17v. 
A la vista de lo reducido de las cantidades invertidas, debemos suponer que el muelle de la ciudad fue objeto tan solo de algunas obras de urgencia que no vinieron a resolver en realidad gran cosa. En efecto, tan solo dos años después, en febrero de 1719, el procurador mayor de la ciudad daba nuevamente la voz de alarma sobre el estado ruinoso que presentaba el muelle de la Puerta del Mar. La ciudad comisionó al mismo procurador mayor para que efectuase un reconocimiento del sitio y evaluase junto a los maestros alarifes de la ciudad el costo de las obras necesarias ${ }^{13}$. Esta inspección dio origen a un pormenorizado informe en que quedó de manifiesto que era necesario reconstruir la esquina del muelle que miraba a la Puerta del Mar y ponerla redonda, para que los barcos que se arrimaban a ella no arrancasen con el roce de sus cascos los cantos de piedra que lo formaban, y lo mismo era preciso en las escaleras del muelle, casi inutilizadas debido a que las gradas estaban muy desgastadas. También era necesario derribar las casillas levantadas en el muelle, una de las cuales, que servía como taberna, amenazaba inminente ruina, con riesgo para las personas que entraban en ella. Los alarifes recomendaron aprovechar la piedra resultante de la demolición para fabricar un trozo de muralla «desde la que viene de la casilla hasta cerca de la escalerilla frente de la cruz», porque allí combatía mucho el mar, causando el deterioro del muelle. Y, asimismo, poner hileras de sillares y solar con cantos la surtida que iba hacia Puntales (que probablemente servía de varadero y, quizás, también como carenero), así como repasar todas las juntas existentes entre las piedras colocadas alrededor de todo el muelle, fijándolas con cal, arena y chinas metidas a punta de palanqueta, debido a que el agua del mar se metía entre ellas dejando en hueco las uniones y amenazando a la obra. El costo de este conjunto de actuaciones se estimó en seis mil pesos.

La ciudad, nuevamente escasa de recursos, dio prioridad en esta ocasión a la reparación más urgente, que era la de la esquina que miraba hacia el Puntal, empleando el producto del arrendamiento de la casilla del propio muelle, y estimó que la conservación de este le correspondía a la Corona, en razón del uso que esta hacía del mismo para los embarques y desembarques de artillería, municiones y demás pertrechos de guerra. Por tanto, acordó representar al rey esta urgencia, como también exponerla al Consulado, directamente interesado también en la conservación en buen estado del muelle por el constante uso que hacía de este el comercio ${ }^{14}$. El Consulado no acudió a esta necesidad con dinero contante, pero condonó a la ciudad dos mil pesos, que eran una parte de la mayor cantidad que le había prestado para la campaña de 1702, cuando Cádiz estuvo sitiado por las

13. AHMC, LAC, año 1719, cabildo de 28 de febrero, fol. $60 \mathrm{v}$.

14. Idem, cabildo de 4 de mayo, fol. 153-155.

Ediciones Universidad de Salamanca / ف®@ Stud. his., H. ${ }^{a}$ mod., 39, n. 2 (2017), pp. 185-219 
armadas enemigas de Inglaterra y Holanda ${ }^{15}$. Este dinero no estaba pronto para ser invertido en la obra, por lo que a comienzos de junio esta aún no había principiado y el procurador mayor recordaba al cabildo su urgencia, puesto que cada día que pasaba se experimentaban nuevos daños en el muelle. La ciudad encontró el medio de aprontar la cantidad referida, que se consignó a cargo del arbitrio moderno del uno por ciento sobre las mercancías despachadas en la aduana, cuya prórroga estaba solicitada. Así, una diputación formada por los capitulares Juan de Tavira y Francisco Roldán de Villalta pudo acometer la ejecución de los trabajos ${ }^{16}$, de cuya conclusión fue informado el cabildo en diciembre. La reparación del muelle, hasta el total de los dos mil pesos cedidos por el Consulado y alguna suma más librada por la ciudad, se concluyó «con la perfección conveniente», pero para su duración la ciudad estimó conveniente mantener el muelle libre de los materiales y provisiones que de manera continúa se acumulaban en él ${ }^{17}$. El cumplimiento de esta providencia, sin embargo, no pudo ser garantizado. En 1722, el muelle de Cádiz presentaba nuevamente un aspecto abigarrado y desordenado. Mientras que la ciudad pretendía que sirviera solo para las faenas de carga y descarga, por él circulaba todo tipo de materiales, como madera, leña, ladrillo teja y paja. La ciudad crecía a buen ritmo y las nuevas obras, tanto públicas como particulares, demandaban el continuo abastecimiento de este tipo de elementos. Además, en el muelle se habían levantado nuevas casillas para la venta de aguardiente y otros productos que estorbaban el tránsito y deterioraban las obras realizadas. El Consejo de Castilla se había negado a la petición de la ciudad de que el mantenimiento del muelle corriera a cargo de la hacienda real, por lo que el problema se hacía más arduo. El asunto de debatió ampliamente en el seno del cabildo, que decidió recurrir al gobernador de la ciudad a fin de que adoptara medidas para remediar el problema ${ }^{18}$.

\subsection{Las obras de ampliación del puerto}

La impresión que desprenden las anteriores actuaciones es que las infraestructuras portuarias urbanas de Cádiz no estaban a la altura de las exigencias

15. Sobre estos hechos, vid. González Beltrán, J. M.: «El asalto angloholandés de 1702 y sus repercusiones en la Bahía de Cádiz», en El asalto anglo-holandés de 1702 a la Babía de Cádiz entre la política internacional y las repercusiones locales. El Puerto de Santa María, 2003, pp. 75-117. La relación de préstamos hechos a la ciudad para afrontar los gastos de esta campaña puede verse en AHMC, LAC, año 1719, cabildo de 28 de febrero, fol. 62v-76v.

16. Idem, cabildo de 2 de junio, fol. 186.

17. Idem, cabildo de 7 de diciembre, fol. 417.

18. AHMC, LAC, año 1722, cabildo de 11 de septiembre, fol. 203. 
derivadas del papel asignado a la ciudad como capital del monopolio del comercio americano y como sede del departamento marítimo. La urgencia de ampliar el espacio portuario era manifiesta y a ella respondieron nuevos proyectos de obras, que corrieron a cargo de los ingenieros militares Ignacio Sala y Bartolomé de Amphoux. En ese momento, la zona portuaria de la ciudad se extendía desde el muelle de la Puerta del Mar hasta la punta de la Cruz. El puerto se encontraba físicamente separado del casco urbano por la muralla de defensa de la ciudad. En su tramo portuario, esta muralla contaba con tres baluartes, denominados de San Felipe, San Antonio y de las Cañas o Santa Cruz. El paso por la muralla a la ciudad se realizaba por dos puertas, llamadas respectivamente Puerta del Mar y Puerta de Sevilla. Junto a la primera de ellas había un muelle que se adentraba en el mar, con diversas escaleras para el servicio de embarque y desembarque (imagen 1).

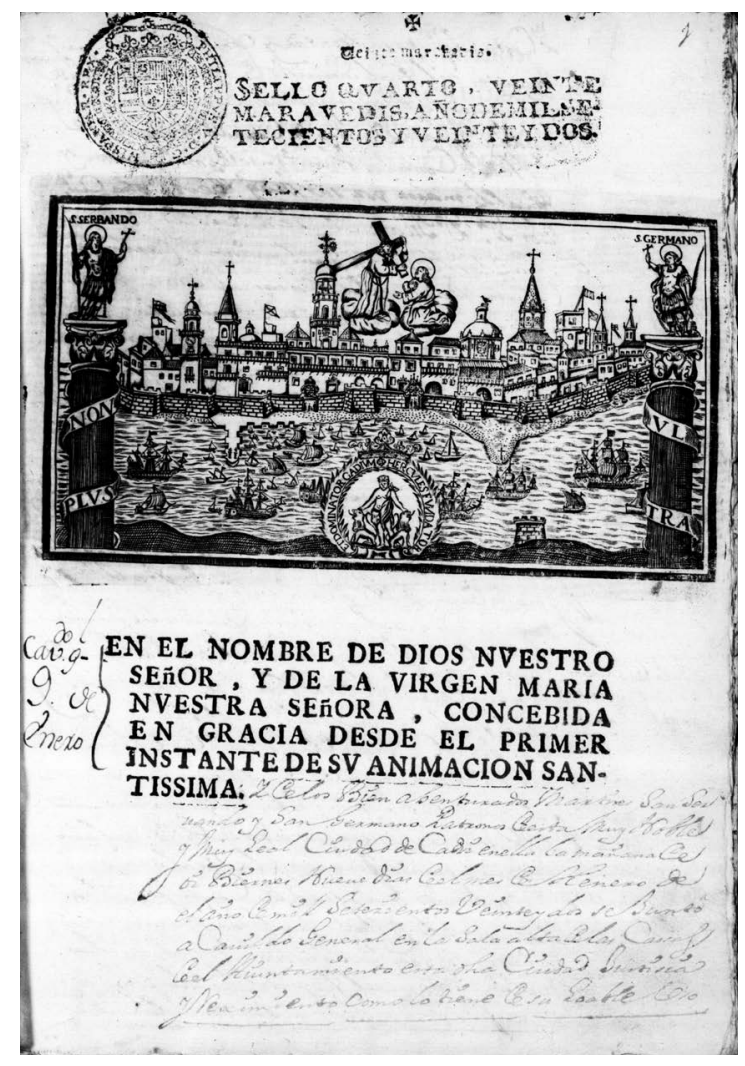

Imagen 1. El puerto de Cádiz en un grabado de 1722. Archivo Histórico Municipal de Cádiz, Libros de Actas Capitulares, Año 1722. 
Frente a la Puerta de Sevilla se llevó a cabo la construcción de otro muelle, a la postre estrecho e incómodo, sobre la línea de costa, en el que se practicaban las cargas y descargas de mercancías durante las pleamares ${ }^{19}$. Este muelle, de reducidas dimensiones, se extendía desde la citada puerta hasta el baluarte de Santa Cruz y contaba con una muralla para contener el agua, que sobresalía por encima del nivel de la pleamar mayor, con una escala desde la línea de muelle hasta su base. Sobre la explanada del muelle se levantaba una casilla de servicio (que fueron más tarde dos) y un área expedita para apilar los frangotes de mercancías. Más allá de la Puerta de Sevilla, hacia el baluarte de San Antonio, se construyó una surtida que bajaba a la playa que descubrían las bajamares (ver imagen 2).

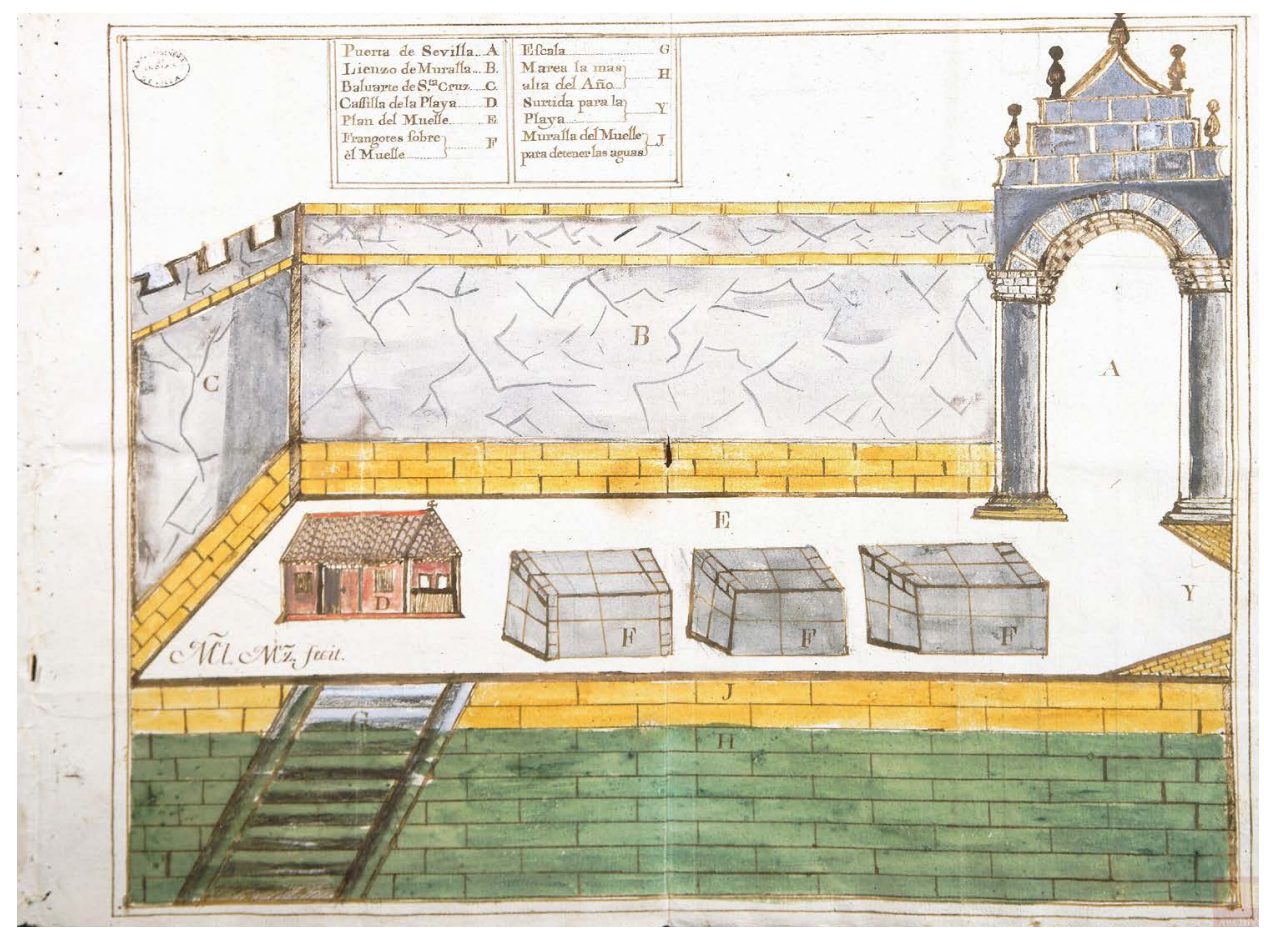

Imagen 2. Vista del muelle proyectado en Cádiz junto a la puerta de Sevilla. Plano de Manuel Martínez, 1745. Ministerio de Educación, Cultura y Deporte. Archivo General de Indias, MP-EUROPA-ÁFRICA, 19.

19. Archivo General de Indias [en adelante AGI], MP-EUROPA-ÁFRICA, 19.

Ediciones Universidad de Salamanca / @®@ Stud. his., H. ${ }^{a}$ mod., 39, n. 2 (2017), pp. 185-219 


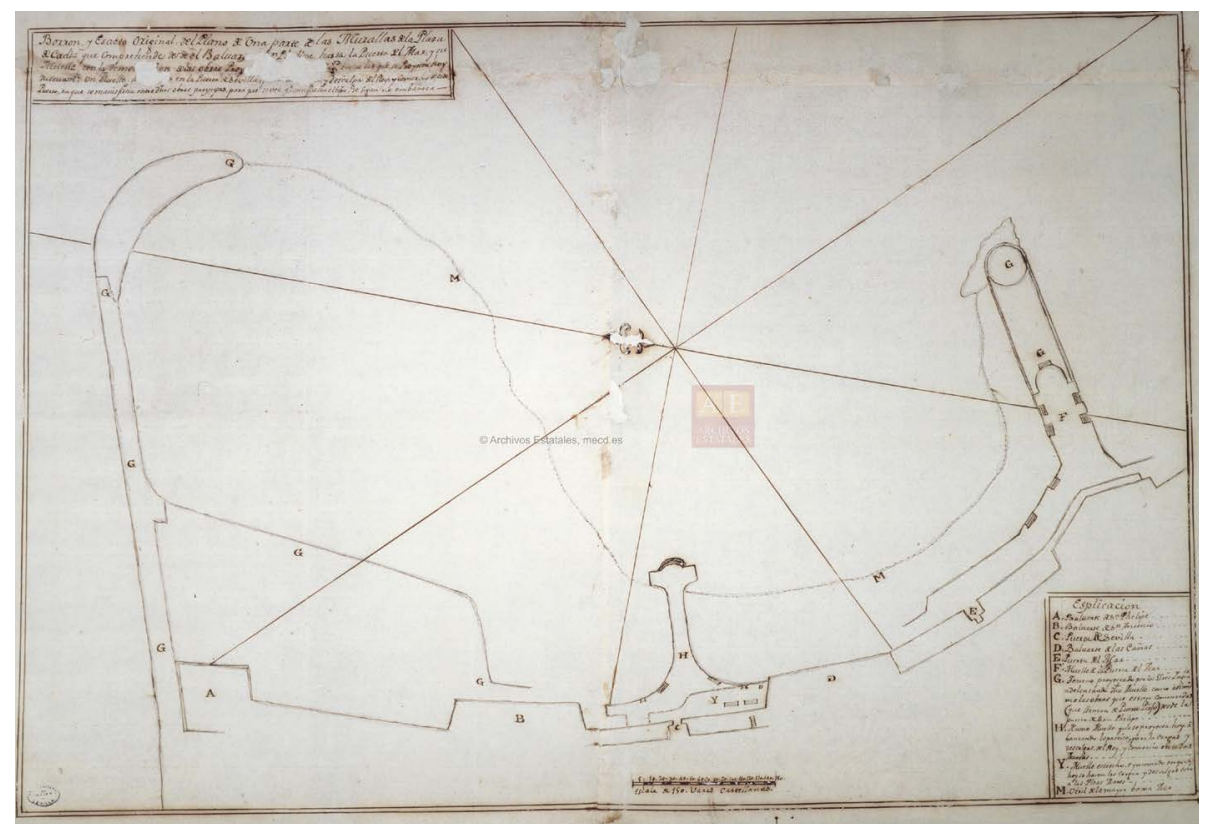

Imagen 3. Plano de las murallas de Cádiz desde el baluarte de San Felipe hasta la puerta del Mar y del muelle con las obras que se proyectan entre ellas un muelle en la puerta de Sevilla. Ministerio de Educación, Cultura y Deporte. Archivo General de Indias, MP-EUROPA-ÁFRICA, 18.

Los proyectos de ampliación acometidos a partir de los años treinta y cuarenta de la centuria contemplaban la prolongación del muelle de la Puerta del Mar, duplicando su longitud; construir un nuevo muelle en la puerta de Sevilla penetrando en el mar, de modo que permitiera cargar y descargar a los barcos del rey y a los del comercio en todas las mareas y, finalmente, construir un espigón en la punta de San Felipe, proporcionando un amplio desembarcadero en la zona conocida como Puerto Piojo (imagen 3$)^{20}$. Las obras de construcción del malecón de San Felipe ya se habían iniciado en 1731. En 1734 se trabajaba en fundamentar y levantar el nuevo muelle de la Puerta del Mar $^{21}$. Asimismo avanzaban las obras

20. AGI, MP-EUROPA-ÁFRICA, 18.

21. Plano y perfiles que demuestran la obra que se ha fundado y levantado en el Muelle de la Puerta del Mar de la Plaza de Cádiz durante el año 1733. Ignacio Sala (1734). AHMC, Sección Planos, sig. G. Perea: Cajón 1, n. ${ }^{\circ} 164$. 
emprendidas entre el baluarte de San Felipe y el de la Cruz ${ }^{22}$. En años sucesivos, los ingenieros encargados de las obras daban cuenta puntual de los progresos que estas iban experimentando, enviando anualmente detallados planos al Ayuntamiento. Hasta 1738 lo hizo Ignacio Sala ${ }^{23}$. Entre 1739 y 1741 los planos conservados están firmados por Bartolomé Amphoux ${ }^{24}$. En 1736 se llevaron también a cabo obras en la Puerta del Mar ${ }^{25}$. Las obras de prolongación del muelle situado junto a esta puerta se prolongaron aún durante un mayor número de años. En 1751 el muelle estaba terminado, contando con una batería situada en su frente, pero sin llegar aún a alcanzar, como estaba planeado, el escollo nombrado de la Galera ${ }^{26}$.

\subsection{La ordenación del espacio portuario urbano}

En los años sesenta y setenta, el incremento de la actividad portuaria provocó que los muelles gaditanos presentaran una situación caótica, no acorde con la importancia mercantil de la ciudad. El desorden se había adueñado de estas instalaciones y los inconvenientes se multiplicaban para sus usuarios. Ello movió a actuaciones por parte del cabildo municipal, que pasaron por un intento de especialización de los espacios portuarios. Quien llamó la atención sobre el asunto fue el procurador mayor de la ciudad, el marqués de Casinas. En abril de 1763, este expuso al cabildo municipal que durante el invierno el muelle se convertía en un gran cenagal, con gran quebranto para el abundante tráfico que hacía uso del puerto. La impresión que provocaba la situación a quienes venían por mar a Cádiz era muy desfavorable:

A todo forastero le causa gran novedad que en una ciudad tan populosa, se vea y no remedie tal incomodidad y quebranto al entrar en ella por su muelle, que pudiera ser el más cómodo y vistoso si estuviera reparado como era debido y quitados todos los estorbos y embarazos que le afean, lo que con especialidad notan los extranjeros ${ }^{27}$.

El abigarramiento del muelle impedía su correcto funcionamiento. Junto a los productos habituales del comercio de largo radio, allí se desembarcaba todo tipo

22. Plano y perfil que demuestran el estado en que se halla el día primero de enero de 1734 la obra que se construye del pie del Baluarte de S. Felipe de la Plaza de Cádiz a las peñas de la Cruz. Ignacio Sala (1734). AHMC, Sección Planos, sig. 5.2.

23. Idem, cajón n. ${ }^{\circ} 1$, sig. 202 (1735), 166 (1736), 168 (1737) y 140 (1738).

24. Idem, n..$^{\circ}$ (1739), 153 (1740) y 2 (1741).

25. Plano y perfiles que demuestran la obra de las Puertas de la Mar de la plaza de Cádiz. Ignacio Sala (1736). AHMC, Sección Planos, sig. G. Perea: Cajón 1, n. 167.

26. Torrejón Chaves, J.: «El área portuaria...», art. cit., p. 131.

27. AHMC, LAC, año 1763, cabildo de 6 de abril, fols. 101-103v. 
de géneros comestibles, leña, carbón, paja, cal, piedra y ladrillo, que provocaban el deterioro de las instalaciones. Además de las casillas de sanidad, el capitán de puerto y el comandante del resguardo de rentas, había otras que estorbaban el embarque de personas y mercancías. Una de ellas fue construida por la Junta de Fortificación para el resguardo de las herramientas de la obra del muelle, pero ahora servía de taberna. Otra le sirvió al asentista de los materiales de la misma obra, cuyos herederos la mantenían y la arrendaban en beneficio propio. Ambas estaban muy mal situadas, en la línea exterior del muelle, cerca de las puertas que comunicaban a este con la ciudad, impidiendo la vista de la Bahía. Otros muchos tendajos de tablas y esteras se acumulaban en el entorno, afeándolo notablemente.

El objetivo del procurador mayor era despejar la línea exterior del muelle, dejándola diáfana y desembarazada, y permitiendo construir a lo largo del mismo una calzada de piedra para su más cómodo tránsito. Asimismo, el regidor propugnaba una distribución razonable de la superficie portuaria en función de los tipos de mercancías. El cabildo otorgó amplio poder al marqués de Casinas para llevar adelante este intento ${ }^{28}$. Meses después, el propósito se había logrado. Se llevaron a cabo obras para dejar el muelle transitable y «de hermosa vista». Se logró que el rey dictara una orden para que el descargadero de cal, piedra, ladrillo, leña y paja pasase a Puerto Piojo, también conocido como Puerto Escondido. Finalmente, se proponía que se abriera en la muralla una nueva puerta de acceso a este paraje para la entrada y salida de este tipo de materiales ${ }^{29}$. Para la ordenación y vigilancia del desembarcadero de Puerto Escondido, la Intendencia de Marina nombró como cabo a Cristóbal Ferrari, quien años después reclamaba a la ciudad un estipendio por su trabajo, sin que el cabildo estimase su petición ${ }^{30}$.

La solución arbitrada no convenció, sin embargo, a los patrones de las embarcaciones que traían carbón a Cádiz desde Algeciras y otros puertos. En 1769 representaban los inconvenientes que para su tráfico tenía Puerto Piojo, debido a que sus barcos varaban en seco, a lo «extraviado» del sitio y a las penalidades que sufrían los mandaderos, por ser el terreno todo de fango. Aunque se les había prometido que se sacaría la punta de aquel muelle más hacia fuera, el ingeniero director de la obra de la nueva Aduana les había notificado que debían abandonar de inmediato aquel varadero, ya que se proyectaba cerrar con una muralla el espacio que mediaba entre el nuevo edificio y la punta del muelle, ofreciéndoles como única solución que el carbón se descargase con cabrias en el otro muelle ${ }^{31}$.

28. Ibidem.

29. AHMC, LAC, año 1763, cabildo de 23 de septiembre, fol. $189 \mathrm{v}$.

30. AHMC, LAC, año 1768, cabildo de 18 de mayo, fols. $232 \mathrm{v}-236$

31. AHMC, LAC, año 1769, cabildo de 15 de julio, fols. $313 \mathrm{v}-315$.

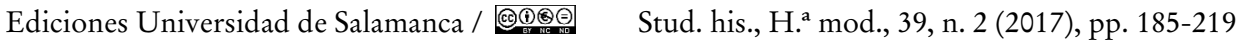


Esto significaba reproducir la situación que se había querido evitar unos años antes, por lo que el cabildo medió ante el director de la obra de la Aduana, quien garantizó que se haría un descargadero cómodo en el nuevo muelle, con surtida proporcionada para el tráfico de carbón ${ }^{32}$.

Los esfuerzos por destinar el muelle principal de la ciudad únicamente a las mercancías transportadas por los barcos del gran comercio europeo y americano se vieron desbordados nuevamente por la realidad en un corto espacio de tiempo. En 1778, la barrilería de agua del puerto embarazaba nuevamente la superficie del muelle de la Puerta del Mar y la ciudad se vio precisada a solicitar al gobernador que ordenase trasladarla a Puerto Escondido ${ }^{33}$. Un año después eran el administrador general de la Real Aduana de Cádiz y el comandante general de los resguardos de rentas los que se dirigían al gobernador de la ciudad para exponerles la situación del puerto. Según alegaron, el muelle de la Puerta del Mar estaba nuevamente atestado de puestos de bebidas y comestibles, y, al mismo tiempo, embarazado por el almacenamiento de agua y materiales de construcción, que ocupaban buena parte de su superficie en detrimento de tráfico de las mercancías del comercio. Para remediarlo, proponían levantar todos los puestos, dejando en el muelle tan solo las garitas de la tropa y las casillas del resguardo, sanidad, Contratación, capitán de puerto y asentista de fortificaciones. De esta forma se limpiaría el muelle y, además, se evitarían los escándalos nocturnos que los tripulantes de los barcos de guerra y comercio provocaban en los establecimientos de bebidas allí ubicados. En segundo lugar, recomendaban una distribución de funciones entre los distintos muelles del puerto de la ciudad: la aguada de los navíos se trasladaría a Puerto Escondido, la pesca entraría por la Puerta de Sevilla, y el vino y los comestibles por la Puerta del Mar. Con esta ordenación se lograría el objetivo principal de mantener diáfano el muelle de la Puerta del Mar, que, como queda dicho, era el principal de la ciudad. Así lo instó el gobernador al cabildo de la ciudad, que aprobó este conjunto de medidas de regulación ${ }^{34}$.

\section{EL POTENCIAL PORTUARIO DE LA BAHÍA Y SU PROBLEMÁTICA}

A pesar de las obras de ampliación a las que fueron sometidas, las instalaciones portuarias urbanas de Cádiz resultaban insuficientes para asumir el conjunto de exigencias derivadas del tráfico comercial europeo y americano que soportaba la ciudad, que se vieron intensificadas a partir de la segunda mitad

32. Idem, cabildo de 29 de julio, fol. 316v.

33. AHMC, LAC, año 1778, cabildo de 10 de septiembre, fols. $224 \mathrm{v}-225$.

34. AHMC, LAC, año 1179, cabildo de 6 de febrero, fols. 79-82v.

Ediciones Universidad de Salamanca / @®@@ Stud. his., H. ${ }^{a}$ mod., 39, n. 2 (2017), pp. 185-219 
del siglo XviI. Los navíos de las flotas de Indias necesitaban surgideros para fondear, amarraderos para las estadías e invernadas, lugares cómodos para la carga y descarga de mercancías, instalaciones de carena, almacenes de mercancías y otros para resguardar los pesados efectos navales que formaban parte de su equipamiento: velas y jarcias fundamentalmente, pero también todo tipo de elementos que transportaba un barco mercante como parte de su equipo. Todo ello exigía una compleja logística para la que la Bahía de Cádiz ofrecía posibilidades y respuestas adecuadas.

En efecto, por el puerto de Cádiz no se entendía solamente los muelles de los que disponía la ciudad, sino también el conjunto de la Bahía y, muy especialmente, el seno interior de la misma, también conocido como Bahía de Puntales. Esta presentaba condiciones muy favorables para acoger a los navíos del rey y a los del comercio. Su entrada era lo suficientemente amplia como para facilitar el paso de grandes buques, pero, al mismo tiempo, lo bastante estrecha como para defender eficazmente a los fondeados en su interior de cualquier ataque por mar, gracias al fuego cruzado de las baterías de los castillos del Puntal y Matagorda. La de Puntales era, por tanto, una bahía protegida y una ensenada natural resguardada para los buques, que disponían allí de buenos fondeaderos. Los caños que formaba proporcionaban también buenos surgideros para los navíos de la Carrera de Indias y lugares adecuados para sus carenas. En el caño de Sancti Petri, junto al Puente Suazo, había estado situado desde fines del siglo xvi un real carenero de los buques de la Armada. En la Carraca se estableció, ya en el xvinI, el arsenal del departamento marítimo de Cádiz. La playa de Puntales servía como astillero y carenero de los barcos de la Carrera de Indias. Y en el caño del Trocadero se establecieron los almacenes e instalaciones de carena del Consulado y de muchos comerciantes y navieros gaditanos. Dentro de la Bahía de Cádiz, aunque fuera de Puntales, El Puerto de Santa María fue también una ciudad de activo comercio, que se beneficiaba del resguardado puerto fluvial de la ciudad a orillas del río Guadalete, y en cuyo término el castillo de Santa Catalina, situado enfrente de Cádiz, contribuía también a la defensa de la Bahía. Todo este conjunto de circunstancias, a las que se unieron el que Cádiz se erigiera en la capital del comercio americano y en la residencia de la capitanía general de la Armada, hizo que la Bahía fuese objeto de numerosos elogios. En 1786, por ejemplo, alguien que por su encargo de capitán del puerto conocía bien sus circunstancias, el brigadier Francisco Javier Muñoz, escribía lo siguiente:

Es el puerto de Cádiz uno de los principales de la Europa; su grande y rico comercio, ventajosa situación para las expediciones marítimas, su bello clima y el ser el principal Departamento de Marina, donde reside el Capitán General de la Armada,

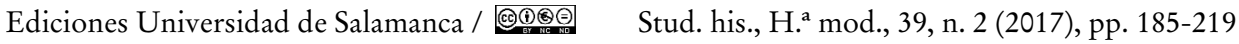


lo ponen en la constitución indispensable de rivalizar con todas las demás naciones de la Europa ${ }^{35}$.

Las condiciones naturales que ofrecía la Bahía de Cádiz para el comercio americano experimentaron, sin embargo, variaciones en el siglo xviII, como resultado de las obras hidráulicas acometidas y, sobre todo, de la propia dinámica que entrañaba el intenso tráfico que acogieron sus aguas. Estos cambios suscitaron temores entre comerciantes y gobernantes, y determinaron actuaciones orientadas al intento de evitar la degradación de la Bahía y a conservar sus condiciones de navegación.

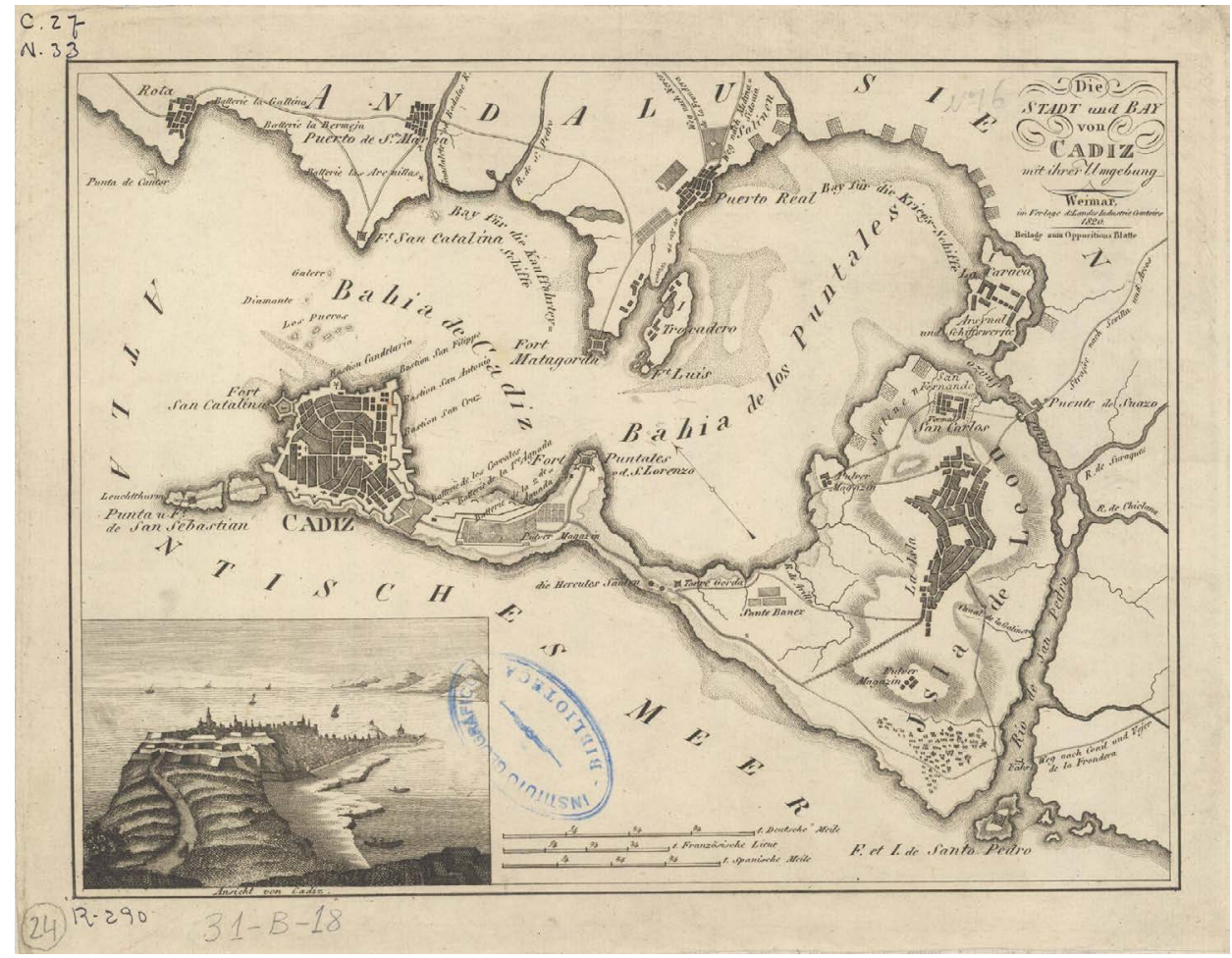

Imagen 4. Bahía de Cádiz. Mapa alemán de 1820. Instituto Geográfico Nacional. Sign.: 31-B-18.

35. AGI, Consulados, 1367, n. $^{\circ} 6$.

Ediciones Universidad de Salamanca / @®@@ Stud. his., H. ${ }^{a}$ mod., 39, n. 2 (2017), pp. 185-219 
JUAN JOSÉ IGLESIAS RODRÍGUEZ

LAS INFRAESTRUCTURAS PORTUARIAS DE LA BAHÍA DE CÁDIZ

ANTE EL RETO DEL MONOPOLIO AMERICANO

\subsection{Las obras de desviación del cance de los ríos Guadalete y San Pedro}

En el siglo xvir, Jerez de la Frontera llevó a cabo obras para desviar el cauce del río Guadalete y unirlo al de San Pedro. Las razones de esta iniciativa no están muy claras, pero parece que tienen que ver con la vieja aspiración de esta ciudad a contar con una salida fluvial al mar para la exportación de la abundante producción agraria de su término. H. Sancho sitúa en 1652 el inicio de los trabajos de rompimiento del Guadalete ${ }^{36}$. La iniciativa perjudicaba directamente los intereses de la vecina ciudad de El Puerto de Santa María, porque convertía la desembocadura del Guadalete en un curso muerto, con un aumento cierto de las posibilidades de aterramiento de la boca del río que amenazaba al tráfico naval por sus aguas. De hecho, El Puerto pleiteó entre 1689 y 1701 con sus vecinos por esta causa ${ }^{37}$.

A las alturas del momento del traslado a Cádiz de la Casa de la Contratación el problema era otro. El río San Pedro formaba unos extensos bajos en su desembocadura, en el paraje conocido como las Cabezuelas, que ponían en peligro el paso de navíos hacia Puntales y que incluso podían llegar a volver impracticable la canal de la Bahía. En 1727, Patiño determinó poner solución a la situación creada, acometiendo obras de desviación del cauce del río San Pedro para reconducir las aguas del Guadalete a su antigua madre, es decir, el canal de El Puerto de Santa María. La ciudad de Jerez de la Frontera, probablemente por la responsabilidad que le cupo en el origen del problema, debía contribuir al financiamiento de las obras aportando la mitad de su costo; la otra mitad sería aportada a partes iguales por Cádiz, El Puerto de Santa María y la Real Hacienda. Dada lo urgente de llevar a cabo la actuación, Patiño ordenó al gobernador de Cádiz, Tomás de Idiáquez, que la ciudad aportase de inmediato quinientos doblones a cuenta del cupo que le tocase en suerte, advirtiéndole que «será cualquiera omisión en este materia muy culpable» ${ }^{38}$.

Esta decisión abrió un proceso de negociación entre el gobierno y las ciudades y, a su vez, en el seno de estas, con objeto de intentar reducir la aportación respec-

36. SAncho de Sopranis, H.: Historia del Puerto de Santa María desde su incorporación a los dominios cristianos en 1259 hasta el año mil ochocientos. Cádiz, 2007, p. 211. En realidad, el año de inicio de las obras fue 1648, según indican J. J. López Amador y E. Pérez Fernández, quienes realizan una actualización de este tema y aportan nuevas informaciones de interés. López Amador, J. J. y Pérez Fernández, E.: El Puerto Gaditano de Balbo. El Puerto de Santa María. Cádiz. Cádiz, 2013, pp. 189-204. Vid. también sobre esta cuestión Pérez Serrano, J. y Román Antequera, A.: «La salida marítima en el Marco del Jerez: transporte fluvial y ferroviario, ¿opuestos o complementarios?», Congreso de Historia Ferroviaria, 2009, en línea: www. docutren.com/HistoriaFerroviaria.

37. Archivo Histórico Nacional, Consejos, 35040, exp. 1.

38. AHMC, LAC, año 1721, cabildo de 1 de septiembre, fols. 316-317v.

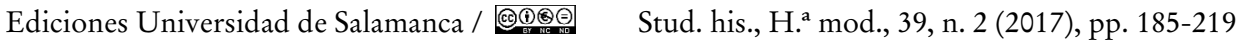


tiva o de encontrar fuentes financieras para poder dar respuestas a las exigencias económicas derivadas de la empresa. La ciudad de Cádiz no disponía de caudales de propios para hacer frente a la entrega de los dos mil pesos demandados por Patiño. A propuesta de su alférez mayor, Juan Gregorio de Soto Avilés, barajó la posibilidad de enajenar la vara de fiscal de la real justicia, que se hallaba vacante, aunque finalmente el cabildo, reunido de urgencia para tratar de la cuestión, decidió sacar dicha cantidad de la bolsa del arbitrio destino a la construcción de la nueva catedral de la ciudad, pidiendo para ello el acuerdo del cabildo eclesiástico ${ }^{39}$. Una nueva y perentoria carta-orden de Patiño al gobernador informaba menos de un mes más tarde del montante total que le tocaba a Cádiz en el pago del costo de la obra, que ascendía a cinco mil pesos, por lo que demandaba la entrega inmediata de otros tres mil pesos, además de los dos mil ya adelantados por la ciudad. El cabildo municipal acordó solicitar una minoración de esta contribución y recurrir de nuevo al cabildo eclesiástico para que prestase la cantidad exigida a la ciudad, con el compromiso de devolver el total de la deuda dentro del año siguiente. Ante los atrasos que sufrían los caudales de propios, el cabildo acordó también solicitar real facultad para sacar los cinco mil pesos de los arbitrios destinados a la construcción de murallas para la fortificación de la ciudad ${ }^{40}$.

Sin embargo, la ciudad solo pudo aportar de inmediato mil pesos más, que fueron puestos a disposición de la tesorería de Marina. Idiáquez escribió a Patiño representándole la imposibilidad en la que se veía la ciudad de hacer frente por el momento al resto de la contribución que se le exigía. Ello motivó una tercera carta de Patiño en la que urgía la entrega de los dos mil pesos restantes hasta completar el total de cinco mil que le habían sido repartidos ${ }^{41}$. El cabildo, a propuesta del procurador mayor, solicitó facultad real para imponer un arbitrio de tres reales en cada arroba de aguardiente que entrase en la ciudad, especie que ya estaba gravada con seis reales en arroba con destino a la fábrica de las murallas ${ }^{42}$, pero ante los nuevos apremios de Patiño, terminó por recurrir nuevamente a un préstamo del cabildo eclesiástico ${ }^{43}$. Aun a costa del endeudamiento de la ciudad con la Iglesia gaditana, la situación parecía, pues, que estaba salvada. Sin embargo, no era así. Jerez de la Frontera había recurrido al rey solicitando la reducción de la cantidad que le había sido asignada, quince mil pesos, la mitad del montante de la obra de reducción de las aguas del Guadalete a su antiguo curso. El monarca accedió a esta

39. Idem, fols. 318-319.

40. Idem, cabildo de 26 de septiembre, fols. 345-347.

41. Idem, cabildo de 3 de octubre, fols. $352-354 \mathrm{v}$.

42. Idem, cabildo de 21 de noviembre, fols. 406v-409.

43. Idem, cabildo de 23 de diciembre, fols. $497 \mathrm{v}-498 \mathrm{v}$. 
rebaja, fijándole ahora a Jerez una contribución de la tercera parte del total. Los otros dos tercios deberían ser aportados a iguales partes por la Real Hacienda y las ciudades de Cádiz y El Puerto. Esto significaba que cada una de estas últimas debía incrementar su aportación en más de mil seiscientos reales.

El cabildo gaditano, no obstante su voluntad de «obedecer ciegamente» las órdenes del rey, no tuvo más remedio que reconocer la imposibilidad en la que se hallaba de atender a esta nueva contribución. Además, el plazo para la devolución del empréstito tomado del cabildo eclesiástico concluía, sin que el arbitrio sobre el aguardiente hubiera rendido todavía suficiente, ya que su concesión era muy reciente. De hecho, la correspondiente real orden fue firmada en 10 de febrero, y además preveía que el producto del arbitrio se aplicara también a gastos de lazareto y sanidad. Ello obligó a la ciudad a adoptar el acuerdo de endeudarse nuevamente, tomando a premio del particular que los ofreciese los cinco mil pesos que debía a la Iglesia ${ }^{44}$. Todos estos problemas de financiación no impidieron que, a las alturas del año 1733, la obra de cerramiento del río San Pedro se encontrara en avanzado estado de realización ${ }^{45}$.

\subsection{Las condiciones de navegabilidad de la Babia}

Tan solo unos años después del traslado a Cádiz de la Casa de la Contratación, en 1726, comenzó a notarse una disminución en la profundidad de las aguas de la Bahía de Cádiz que, lejos de detenerse, siguió en aumento hasta hacer saltar las alarmas. En 1737 se reconocía que el canal de la Bahía presentaba una braza menos de calado que unos años antes. En algunos parajes la mengua era aún mayor, lo que no dejaba de producir cuidado, «siendo el tráfico y comercio marítimo de esta ciudad por medio de su Bahía uno de los mejores de Europa» ${ }^{46}$. El cabildo municipal gaditano nombró por sus comisionados para estudiar este problema a dos de sus miembros, Pedro Colarte y Manuel de Barrios, diputados de obras («obreros mayores»), ambos vinculados a dos de las más importantes familias de comerciantes instaladas en Cádiz ${ }^{47}$.

44. AHMC, LAC, año 1722, cabildo de 19 de mayo, fols. 112v-114.

45. AHMC, LAC, año 1733, cabildo de 15 de abril, fols. 117-118.

46. AHMC, LAC, año 1737, cabildo de 19 de enero, fol. 32.

47. Pedro Francisco Colarte y Morla, el más activo a la postre de los dos, era hijo de Carlos Francisco José Colarte, $2^{\circ}$ marqués de El Pedroso, y de la jerezana Luisa Paula Morla Villavicencio. A su vez, era nieto de Pedro Colarte o Colaert, comerciante flamenco natural de Dunquerque instalado en Cádiz a mediados del siglo xvir. Fue caballero de Santiago, gentilhombre de boca del rey y regidor perpetuo y preminente del Ayuntamiento de Cádiz. A la muerte de su padre, heredó el título de marqués de El Pedroso. Vid. Bustos Rodríguez, M.:

Ediciones Universidad de Salamanca / 요 Stud. his., H. ${ }^{a}$ mod., 39, n. 2 (2017), pp. 185-219 
Los «diputados de Bahía», como fueron conocidos desde entonces y en quienes el cabildo depositó su absoluta confianza, recibieron el encargo de averiguar los perjuicios que aquella padecía y de cotejar los sondeos que hicieren con los efectuados en los pasados años veinte de aquel siglo. Para cumplir este cometido se acordó que el mayordomo de propios de la ciudad pusiera a su disposición los fondos que necesitasen ${ }^{48}$. En cumplimiento de su encargo, llevaron a cabo un sondeo de la Bahía y levantaron el correspondiente plano, por el que se interesó el Real Almirantazgo, que, por mano de su secretario, don Zenón de Somodevilla, ordenó mandar una copia al Infante Almirante don Felipe ${ }^{49}$. Como parte de su comisión, Colarte y Barrios recabaron también los informes de los pilotos prácticos de la Bahía, en su calidad de expertos conocedores de la navegación en la misma. Este conjunto de declaraciones, ocho en total, representa una fuente excepcional para conocer los problemas de degradación que estaba experimentando la Bahía de Cádiz, tanto más preocupantes cuanto que sus aguas acogían a los navíos de la Carrera de Indias, a los barcos del comercio europeo y a los barcos de guerra de la Armada.

El sondeo de la Bahía comenzó a realizarse en abril de 1737 y se prolongó durante cinco meses y medio. Asistieron a él los dos diputados del cabildo, el piloto de la Real Armada Francisco José de Mendinueta y los pilotos prácticos del puerto gaditano Antonio y Manuel Romero, padre e hijo, el primero de ellos con una experiencia de más de cincuenta años como práctico de la Bahía. A resultas del sondeo, se confeccionó un detallado plano bajo las directrices de José Cabezas, teniente de navío, del que se sacó una copia que se remitió al infante almirante en una caja de plata «cincelada y ricamente dispuesta» ${ }^{50}$. Los gastos de todas estas operaciones ascendieron a 475 pesos de plata antigua ${ }^{51}$.

La coincidencia entre los dictámenes que emitieron los prácticos fue muy elevada ${ }^{52}$. Para estos expertos pilotos, las causas de la pérdida de calado de la Bahía eran fundamentalmente las obras que en sus orillas se estaban practicando, la mala

Burguesía de negocios y capitalismo en Cádiz: los Colarte (1650-1750). Cádiz, 1991. Manuel de Barrios y la Rosa descendía de dos familias de comerciantes de origen portugués, también instalados en Cádiz en el siglo xvir. Ocupó el cargo de alguacil mayor de la ciudad.

48. AHMC, LAC, año 1737, cabildo de 2 de mayo, fol. 206.

49. Sobre esta institución, vid. Pérez Fernández Turégano, C.: «El Almirantazgo del infante don Felipe (1737-1748). Conflictos competenciales con la Secretaría de Estado y del Despacho de Marina», Anuario de Historia del Derecho Español, LXXIV, 2004, pp. 409-473.

50. AHMC, LAC, año 1738, cabildo de 20 de septiembre, fols. 571-572.

51. Extracto de trabajos y cuentas del sondeo de la Bahía, presentado por don Pedro Colarte. AHMC, LAC, año 1738, cabildo de 13 de diciembre, fols. 714v-716.

52. AHMC, LAC, año 1738, cabildo de 15 de enero, fols. $15 \mathrm{v}-25 \mathrm{v}$. 
costumbre de vaciar lastres y otros materiales en el fondo de sus aguas y la formación de bajos en torno a los buques naufragados. Las impresiones que transmitieron sobre el estado de la Bahía no eran muy halagüeñas. El fondo había experimentado una disminución de una braza en la última década. Las dos cabezuelas situadas en la entrada para el Puntal habían avanzado, casi juntándose la una con la otra. Ningún práctico se atrevía ya a pasar por allí con un navío de línea. Los bajos de Santo Domingo también habían crecido, dificultando la navegación. Estos bajos se habían extendido más de veinticinco brazas hacia la canal y habían provocado en 1735 que varara un navío del rey, el Hércules. La Bahía, según la pesimista declaración del práctico Manuel Romero, se hallaba perdida in totum, hasta el punto de que en aquellos momentos resultaba difícil que fondearan en ella más de cuarenta naos, cuando a mediados del siglo XVII anclaban cómodamente el doble $^{53}$. Incluso se verificaba la circunstancia de que los barcos longos, que hasta 1729 amarraban a un tiro de pistola de Cádiz, ahora no podían ni acercarse a esta ciudad, e incluso las falúas pequeñas sufrían dificultades. El panorama, en suma, no era muy alentador y apuntaba a una preocupante situación de degradación progresiva de la Bahía.

Las causas de esta situación ya han quedado apuntadas. Los prácticos exponían las que, en su experimentada opinión, motivaban el problema. En primer lugar, las obras realizadas en la Bahía. El cerramiento del río San Pedro, desviando nuevamente su corriente hacia el Guadalete, había provocado la práctica obstrucción de la boca del primero de ellos, por donde ya no podía navegar ni una falúa, así como el aumento de la extensión de los bajos de las Cabezuelas, en los cuales ya no se podía voltejear con ningún navío ni fragata para entrar o salir de Puntales, lo que años antes todavía era posible practicar. El mismo año 1737, de hecho, había tocado de popa en aquel paraje el navío de la Armada llamado el León, por no haber podido bornear sobre los cantiles de la canal. Las obras del muelle nuevo que se estaba construyendo en el baluarte de San Felipe eran también señaladas como causa del deterioro de las condiciones de navegación, pues habían originado la formación de unos bajos que los barcos pequeños que transbordaban mercancías y personas desde los navíos anclados en la Bahía hasta el puerto de Cádiz tenían que sortear botando con las palancas hasta alcanzar la canal. Estos bajos amenazaban con juntarse con los de Santo Domingo, debido a que las obras habían forzado un cambio de dirección en las corrientes de las mareas, las cuales arrastraban materiales que iban a parar a aquellos bajos, en detrimento de la profundidad del agua. En opinión de Antonio Romero, que acumulaba más

53. Idem, fols. 17-18. 
de cincuenta años como práctico del puerto, en el plazo de solo veinte años no se podría amarrar por esta causa en la Bahía ningún navío de guerra ni particular ${ }^{54}$.

La segunda causa de la pérdida de fondo de la Bahía era la costumbre de deslastrar en su interior los barcos mercantes, sobre todos los extranjeros. Bien por comodidad o por ahorrar gastos, muchos barcos alijaban lastre en la Bahía. El lastre, que consistía habitualmente en arena o piedras, iba a parar al fondo, perjudicando a la navegación. Algo similar ocurría con las carenas, cuyos descombros, formado por astillas, cascos de botijas, cascajo, etc., iban a para a la mar en todos los careneros de la Bahía, ubicados en el Trocadero, el Puntal y la Carraca. Además de la acumulación de materiales en el fondo y la consiguiente disminución de la profundidad del agua, estos desechos rozaban y cortaban los cables de los barcos fondeados, causando así una mayor cantidad de perjuicios. Así, por ejemplo, el piloto mayor de la Bahía y Arsenales de Cádiz, Gregorio Francisco de Burgos, evitaba fondear navíos en Puntales a boca del Trocadero, "por razón de tener conocido ser sitio puerco y de muchos ratones (que vulgarmente llamamos nosotros) y estos rozan y cortan los cables» ${ }^{55}$.

Los restos de navíos hundidos representaban un peligro añadido para la navegación en la Bahía, no solo por sí mismos, sino también porque alrededor de ellos se acumulaban materiales que terminaban por generar nuevos bajos. Así ocurría cerca de Fort-Luis, donde se echaron a pique varios barcos durante el asalto anglo-holandés de 1702. Otro de los buques hundidos en aquella ocasión fue a parar al veril de la Bahía en las proximidades de la cabezuela del sudoeste, provocando que esta se prolongase hasta seis brazas en dirección de la canal. Igualmente, en los bajos de Santo Domingo permanecía el casco de un navío francés que echaron a pique los barcos de la Armada española y que generaba remansos que dificultaban la navegación ${ }^{56}$. Los prácticos apuntaban, finalmente, a otros problemas que sufría la Bahía. La escollera del castillo de San Sebastián se la iba comiendo la fuerza del mar y, además, la población se llevaba de la Caleta cantos, piedras y arena para utilizarlos en la construcción. El agua de lluvia hacía que bajara por el desagüe del río San Pedro gran cantidad de broza que iba a parar a la Bahía. El bajo de los Frailes, por último, se había agrandado debido a que el mar de leva arrancaba piedras en los parajes de las Puercas y los Cochinos que iban a parar a su fondo.

54. Ibidem.

55. Idem, fols. $19 \mathrm{v}-21 \mathrm{v}$. Los «ratones», en el argot marinero, son las piedras y materiales puntiagudos y cortantes que están en el fondo del mar y rozan los cables de los barcos. Cursiva nuestra.

56. Ibidem. 
El cabildo gaditano se tomó muy en serio esta problemática. Era mucho lo que la ciudad se jugaba. Estaban en juego, también, los intereses de la Armada y los del comercio europeo y americano. Así pues, el cabildo elevó al almirante general las declaraciones de los prácticos de la Bahía y escribió cartas al marqués de Mari, a don Francisco Cornejo y don Rodrigo de Torres, tenientes generales de la Real Armada, y a Zenón de Somodevilla, secretario del Almirantazgo, para interesarlos en el asunto ${ }^{57}$. Asimismo, los diputados de Bahía del cabildo giraron visita a don Francisco de Varas Valdés, intendente general de Marina y Presidente de la Casa de Contratación, y a don Gabriel de Alderete, marqués de Casinas, como jefe de escuadra y comandante de la Real Armada, a fin de solicitarles que concurriesen por su parte con los informes oportunos ${ }^{58}$. Poco tiempo después llegaban noticias de que el gobierno había firmado un asiento con una compañía catalana para rastrear el fondo de la Bahía ${ }^{59}$. La ciudad, por su parte, renovó y amplió a sus diputados las facultades que tenían para que llevasen a cabo todas las diligencias conducentes a resolver los problemas planteados ${ }^{60}$.

En 1740, Pedro Colarte comunicó al cabildo que había llegado a su noticia que el rey había ordenado a don Francisco de Varas y al comandante de Marina don Juan Navarro que se hiciera una nueva inspección, sondeo y reconocimiento de la Bahía ${ }^{61}$. El asunto no era solo de la incumbencia de la ciudad y de su comercio, sino también una cuestión de Estado. En efecto, Varas recibió varias cartas del secretario del Almirantazgo ordenándole que se señalara un paraje en la Bahía donde los barcos deberían vaciar el lastre obligatoriamente ${ }^{62}$, que se hiciera un nuevo fondeo de este puerto y se levantara plano del mismo ${ }^{63}$, y, por último, que este trabajo se encargara al ingeniero José Barnola, antes de que este embarcara con destino a América ${ }^{64}$. El 24 de julio se celebró una junta presidida por el intendente general de Marina, con la asistencia del jefe de escuadra de la Armada y comandante del Departamento marítimo de Cádiz, don Juan José Navarro, los diputados Colarte y Barrios, el ingeniero Barnola y el práctico del puerto Manuel

57. Las respuestas a estas misivas de la ciudad pueden verse en el libro de actas capitulares del año 1739, fol. 677 (Zenón de Somodevilla), 678 (Francisco Cornejo), 679 (Rodrigo de Torres) y 680 (marqués de Mari).

58. AHMC, LAC, año 1738, cabildo de 15 de enero, fols. $25 \mathrm{v}-26$.

59. AHMC, LAC, año 1738, cabildo de 15 de marzo, fols. 148-149v.

60. AHMC, LAC, año 1738, cabildo de 23 de mayo, fol. $279 \mathrm{v}$.

61. AHMC, LAC, año 1740, cabildo de 10 de junio, fol. 548.

62. De Zenón de Somodevilla a Francisco de Varas y Valdés. Aranjuez, 30 de mayo de 1740. Copia en AHMC, LAC, año 1740, cabildo de 6 de agosto, fol. 711.

63. Idem, fol. 712 .

64. De Zenón de Somodevilla a Francisco de Varas y Valdés. Aranjuez, 20 de junio de 1740. Idem, fol. 713. 
Francisco Romero, como el más «escogido y especulativo» de su profesión, para tratar, en cumplimiento de las órdenes del Almirantazgo, acerca del mejor modo de conservar la Bahía ${ }^{65}$.

Por lo que respecta al problema de los lastres, la junta constató que los cónsules de las naciones extranjeras de Cádiz no habían prestado su colaboración para lograr que los barcos de sus respectivas banderas se sometieran a la inspección de los que transportaban y se avinieran a no arrojarlos en el interior de la Bahía. Debido a ello, la junta acordó hacerle patentes al Almirantazgo las reglas que en esta materia se observaban en otros países y la obligación de cumplir en España las mismas normas en virtud de la correspondencia entre todos los Estados de Europa a que estaban obligados por los tratados de paz internacionales. La junta estimó que el lugar apropiado para alijar lastres era la parte sur de la ciudad, entre el baluarte de los Mártires y la Puerta de Tierra, fuera por tanto de la Bahía y a buena distancia de ella. De este modo no se perjudicarían los fondos de la Bahía; antes bien al contrario, se beneficiaría la conservación de las murallas de Vendaval, ya que la resaca formaría un banco inmediato a ella protegiéndola así del embate del mar. Para ello se establecería un canon equitativo y moderado por tonelada de lastre, con cuyo producto se podría costear una o dos tartanas encargadas de recibir el alijo y transportarlo al lugar señalado. Esta era la práctica que se observaba habitualmente en el puerto de Málaga con los pontones empleados en su dragado, que estaban asistidos por dos tartanas dotadas de compuertas en el fondo que recibían los materiales extraídos y transportaban la carga mar adentro para arrojarla a distancia del puerto.

En lo tocante al nuevo sondeo de la Bahía, la junta determinó que se facilitaría una falúa real al encargado de realizarlo. Este sería, como había dispuesto el Almirantazgo, el ingeniero José Barnola, asistido del teniente de fragata y primer piloto de los bajeles de la Armada Antonio de Matos y del citado práctico Manuel Francisco Romero. También se ofreció a acompañarlos el propio jefe de escuadra, Navarro. Este equipo, junto con la correspondiente dotación, sondearía los principales lugares de la Bahía en la bajamar más escorada y en las pleamares más vivas, a fin de medir las cotas de profundidad y determinar el aumento o disminución del nivel del agua, así como también constatar la consistencia de los fondos, levantando de todo el plano más exacto y cotejándolo con el anteriormente realizado. El cabildo de la ciudad acordó facultar a Colarte para librar las cantidades precisas para pagar los jornales y fletes que se utilizaran en las labores de sondeo ${ }^{66}$.

65. AHMC, LAC, año 1740, cabildo de 6 de agosto, fols. 714-717.

66. Idem, fol. $710 \mathrm{v}$. 
Las operaciones se iniciaron en el mes de septiembre de 1740. En octubre del año siguiente, Barnola comunicaba su conclusión. Además de las mediciones que anteriormente llevó a cabo de la Bahía, sus ensenadas, caños y surgideros, había sondeado los fondos de cantil a cantil y en toda la circunferencia de la ensenada, desde los caños interiores de los reales arsenales y Sancti Petri hasta fuera del puerto, formando con todo un plano general. Refería los muchos gastos que había tenido que realizar y los empeños que a causa de ellos estaba sufriendo, por lo que pedía que estos desembolsos le fueran compensados por el Ayuntamiento de Cádiz ${ }^{67}$. Barnola dejó por escrito el método que había utilizado en el sondeo, a fin de que pudiera aplicarse en operaciones similares sucesivas ${ }^{68}$. Mientras tanto, se producían nuevos incidentes. Cerca de la obra del nuevo muelle del baluarte de San Felipe se quemó y fue a pique un navío. El casco y la quilla hundidos suponían un peligro para las embarcaciones menores que traficaban por aquel paraje ${ }^{69}$. El gobierno no terminaba de dar soluciones al problema de la Bahía. El ministro Campillo ordenó sacar tres copias del plano del sondeo realizado por Barnola y que le fuera remitida una de ellas. Asimismo, dispuso que Barnola realizara un nuevo sondeo ${ }^{70}$. La ciudad, alarmada por los costos que ello representaría y por los atrasos que sufrían los caudales de propios, solicitó pedir facultad para emplear el sobrante del valimiento impuesto sobre el consumo de vino, vinagre y carne ${ }^{71}$, a lo que Campillo accedió ${ }^{72}$.

Entre tanto, Campillo ordenó a la Junta de Obras Reales que se hicieran tres pontones y seis gánguiles para limpiar el puerto de Cádiz y el fondo de la Bahía, costeándose su construcción y mantenimiento de los arbitrios destinados a obras, y supeditando la realización de estas al fin indicado, «respecto de que en el actual estado se tiene por más necesaria y ejecutiva la expresada providencia» ${ }^{73}$. La averiguación del costo de los pontones se encargó a Ciprián Autrán, quien informó que

67. De José Barnola a Francisco de Varas y Valdés. Cádiz, 14 de octubre de 1741 (copia). AHMC, LAC, año 1740, cabildo de 10 de noviembre, fols. 414-415v. Barnola pidió trescientos doblones de sesenta reales de gratificación, aunque finalmente se avino a recibir solamente la mitad, nueve mil reales. AHMC, LAC, año 1742, cabildo de 9 de agosto, fols. 300-302.

68. «Ynstruccion y Metohodo con que se hizo el fondeo de la Bahía, y Puerto de Cadiz, en el mes de septiembre del año de 1740, baxo de cuyo regimen se puede executar en adelante». AHMC, LAC, año 1743, fols. 556-561 (imagen n. ${ }^{\circ}$ 5).

69. AHMC, LAC, año 1742, cabildo de 18 de octubre, fol. 404.

70. De José del Campillo a la ciudad de Cádiz. San Ildefonso, 7 de octubre de 1742. AHMC, LAC, año 1742, cabildo de 18 de octubre, fols. 401v-404.

71. Ibidem.

72. De José del Campillo a la ciudad de Cádiz. San Lorenzo, 1 de diciembre de 1742. AHMC, LAC, año 1742, fol. 450.

73. De José del Campillo a la Junta de Obras Reales de Cádiz. San Ildefonso, 7 de octubre de 1742 (copia). AHMC, LAC, año 1749, cabildo de 26 de abril, fols. 77v-82.

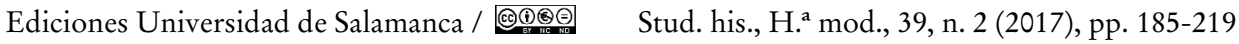


se necesitarían 633.488 reales de vellón, más 267.803 reales anuales para su conservación. Ante lo excesivo de estas cantidades, se acordó encargar por el momento la construcción de solo dos pontones y que se indagase en Málaga, Barcelona y otras partes si se podrían conseguir a menor precio. Los pontones no llegaron al parecer a construirse, pues no se encontró quien quisiera encargarse de ello ni en Cádiz ni en otras ciudades en las que se pregonó la oferta, como Málaga, Tarifa o Algeciras ${ }^{74}$.

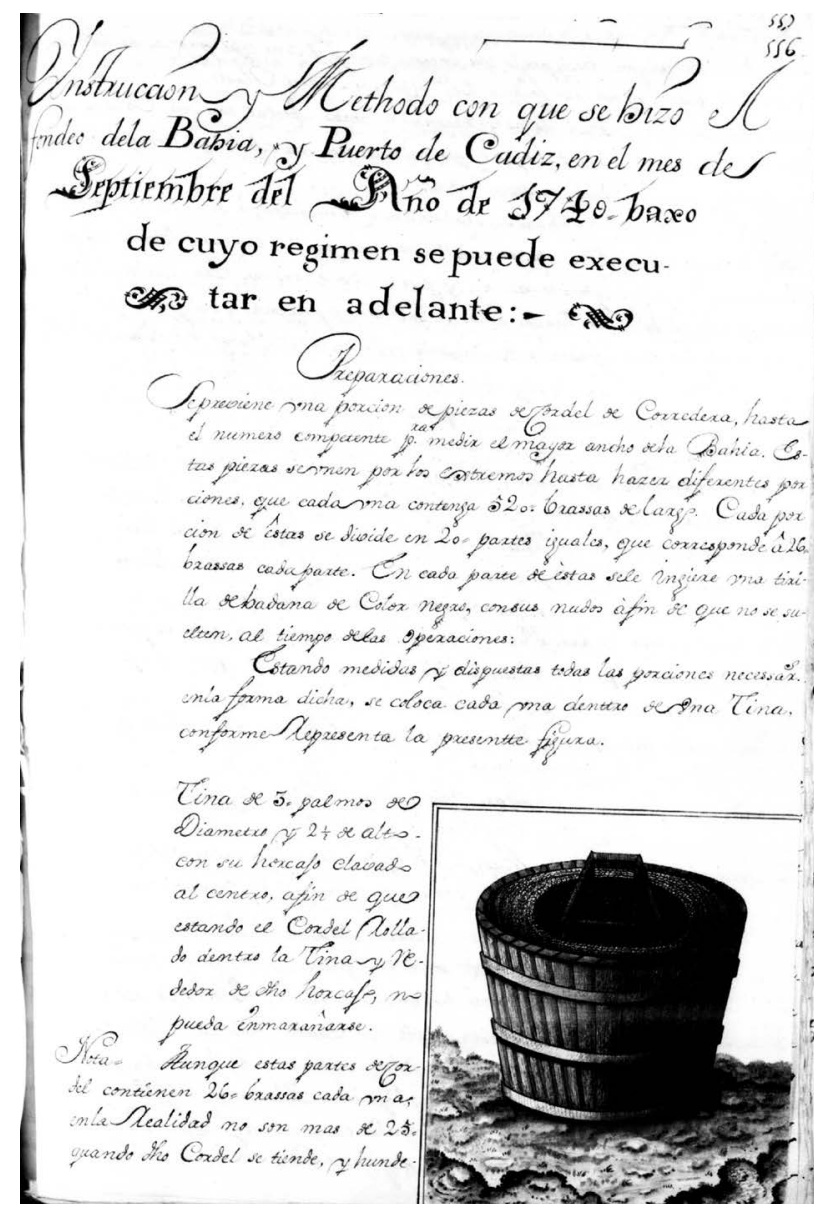

Imagen 5. «Instrucción y método con que se hizo el fondeo de la Bahía y Puerto de Cádiz», por José Barnola. AHMC, LAC, Año 1740.

74. Ibidem.

Ediciones Universidad de Salamanca / @®@@ Stud. his., H. ${ }^{a}$ mod., 39, n. 2 (2017), pp. 185-219 
El nuevo sondeo ordenado por Campillo también quedó en suspenso. En julio de 1743, el marqués de Ensenada reiteraba al cabildo gaditano la orden ${ }^{75}$. El asunto, a pesar de su importancia, parecía haber caído en el olvido, lo que puede interpretarse como sintomático de una mejora de las condiciones de la Bahía. Pedro Colarte, ya marqués de El Pedroso, recordó a la corporación municipal todos los antecedentes, como uno de los mejores conocedores que era del asunto. La ciudad dio las gracias a sus diputados "por el celo y actividad que han tenido en negocio tan importante a esta ciudad y su comercio», y acordó solicitar que a la mayor brevedad se convocara una nueva junta en la que se integraran las personas que se tuvieran por «más inteligentes y celosas del bien común de esta ciudad y permanencia de su Bahía», a fin de que propusieran los medios más convenientes para mantenerla navegable, ya fuera la demolición de alguna de las obras realizadas, el cerramiento de la boca de algún río o la desecación de las salinas. Esta junta debía analizar también la conveniencia de traer pontones para la limpieza de los fondos de la Bahía ${ }^{76}$.

Tan solo unas semanas después, los prácticos emitían un nuevo informe elevando su parecer sobre la situación. Constataban un ligero aumento del agua en distintas partes de la Bahía, que estimaban conveniente conservar. Para lograrlo, insistían en la necesidad de que los lastres se alijaran en lugares donde los recios vientos que reinaban en Cádiz y la resaca de las mareas vivas no los arrastraran hacia el interior del puerto. También recomendaban prohibir que los barcos que embarcaban en Puerto Real y otras partes materiales de construcción con destino a las ingentes obras que se hacían en la ciudad cargasen por encima de la capacidad de su buque, puesto que, con frecuencia, si las condiciones de navegación empeoraban, se veían precisados de arrojar parte de la carga. Finalmente, dado que el mayor aumento del calado del agua se experimentaba cerca del castillo de Santa Catalina, en El Puerto de Santa María, los prácticos pensaban que este fenómeno se debía al efecto de la corriente del Guadalete, por lo que opinaban que también debía facilitársele al río San Pedro la salida de su corriente desde el primer recodo de este río hasta la línea del ángulo del baluarte de Santa Elena ${ }^{77}$.

La mejora, no obstante, era pasajera. En 1749 algunos capitulares volvieron a plantear el mal estado en que se hallaba la Bahía y reiteraban la necesidad de impedir que los barcos extranjeros arrojaran lastre a sus aguas ${ }^{78}$. Para entonces, el

75. Del marqués de la Ensenada a la ciudad de Cádiz. Aranjuez, 23 de junio de 1743. AGMC, LAC, año 1743, cabildo de 3 de julio, fol. 335.

76. AHMC, LAC, año 1743, cabildo de 21 de noviembre, fols. 552-563.

77. AHMC, LAC, año 1743, cabildo de 13 de diciembre, fols. 592-593.

78. AHMC, LAC, año 1749, cabildo de 9 de abril, fol. 64 . 
marqués de El Pedroso, principal impulsor de la regeneración de la Bahía, se hallaba enfermo y no se encontraba en la mejor disposición para continuar su meritoria labor. Un nuevo compás de espera se abría, después de tantos esfuerzos y desvelos como se habían invertido en este objetivo, fundamental para los intereses de la ciudad, en general, y muy particularmente para los de su activa clase mercantil.

\section{Un arsenal para la Carrera de Indias: el caño del Trocadero}

El traslado a Cádiz del Consulado de Cargadores a Indias vino seguido, poco tiempo después, del nuevo asiento realizado por la Corona con esta institución para que corriera a cargo de los navíos de aviso enviados a Indias ${ }^{79}$. Este compromiso enfrentó al Consulado a la necesidad de contar con una flota propia y, por tanto, con instalaciones adecuadas para el almacenamiento de efectos navales y la carena de buques. El lugar elegido para ello fue el caño del Trocadero, un paraje natural que parecía reunir las condiciones adecuadas para asumir aquellas funciones. El Trocadero ya había sido utilizado como surgidero de los navíos de la Carrera de Indias en el siglo xvir. Entre 1647 y 1678 se constata que al menos 22 embarcaciones, entre navíos, fragatas, urcas y pataches, salieron del Trocadero en las flotas de Indias ${ }^{80}$. La existencia de carenas en el caño parece remontarse también a aquel siglo, a tenor de la noticia incluida en un documento de 1698 en el que el Consejo de Indias manifestaba haber recibido una carta por la que Juan de Orbea comunicaba que tenía un navío que había de llevar a Buenos Aires en la boca del Trocadero y que su carena quedaría concluida en cuatro días ${ }^{81}$. A imitación del Consulado, muchos cargadores y navieros construyeron también a orillas del Trocadero almacenes e instalaciones de carena. El caño contribuyó también al reforzamiento de las defensas de la Bahía de Cádiz, desde que durante la Guerra de Sucesión se construyera en su boca de entrada el castillo de Fort-Luis ${ }^{82}$.

Las bondades naturales que reunía el Trocadero como amarradero y carenero para los buques de la Carrera de Indias se veían, sin embargo, empañadas por la constante acumulación de fango que las mareas arrastraban al fondo del caño, disminuyendo su calado y entorpeciendo la navegación. Las características de los terrenos en los que se ubica el Trocadero determinan esta dinámica natural,

79. Vallejo García Hevia, J. M.a : «Los navíos de aviso y los correos marítimos a Indias (1492-1898)», Ius fugit. Revista interdisciplinar de estudios histórico-jurídicos, 7, 1998, pp. 197-268.

80. Iglesias Rodríguez, J. J.: «El 'canal prodigioso'...», art. cit.

81. AGI, Buenos Aires, 4, L.12, fol. 47v.

82. Fernández Cano, V.: Las defensas de Cádiz en la Edad Moderna. Sevilla, 1973, p. 152.

Ediciones Universidad de Salamanca / ®ㅛ Stud. his., H. ${ }^{a}$ mod., 39, n. 2 (2017), pp. 185-219 
que terminó por representar un serio inconveniente para el comercio gaditano. Las ventajas que entrañaba el Trocadero determinaron, sin embargo, una férrea voluntad de superar este impedimento, al que se sumaba el que provocaban los desechos de las carenas que se arrojaban al fondo. Ya en 1717, José Patiño planeó limpiar el caño con pontones de dragado y estaquear sus cantiles para detener los depósitos de lodos. La coincidencia de esta iniciativa con la creación del departamento marítimo y del arsenal de la Carraca, así como con el traslado de las instituciones rectoras de la Carrera de Indias, demuestra la existencia de una estrategia general en el gobierno de Felipe V, que veía en la Bahía de Cádiz un eje fundamental de la política atlántica española ${ }^{83}$. Sin embargo, el dragado del Trocadero, tarea técnicamente compleja y desde el punto de vista económico costosa, no llegó a ejecutarse por el momento y aún se demoraría un tiempo.

En 1738, a tenor de los informes de los prácticos del puerto de Cádiz, el caño presentaba una situación preocupante. Según Gregorio Francisco de Burgos, el Trocadero estaba «totalmente perdido», de modo que los navíos que entraban en él para carenar se quedaban varados en seco durante las bajamares. La mala costumbre de arrojar a sus aguas los desechos y escombros de los navíos, tanto durante las carenas como en las invernadas, era la causa de esta lamentable circunstancia ${ }^{84}$. Alonso Bernal, práctico de la Bahía y guarda principal del Trocadero, indicaba también que la boca del caño se estaba cerrando por la parte de Fort-Luis y Matagorda, al punto que podría llegar el caso de no poder amarrar allí ningún navío ${ }^{85}$. Por su parte, Diego Carcaño insistía en el daño que provocaban los escombros de las carenas, en los que se mezclaban los cascos de botija, los pedazos de frascos y limetas y los retazos de maderas pesadas que iban a parar al fondo e iban disminuyendo el calado del canal ${ }^{86}$. El cabildo gaditano hizo averiguaciones para saber a quién correspondía la limpieza del Trocadero, comprobando que el Colegio de San Telmo de Sevilla tenía asignada esta responsabilidad, para cuyo cumplimiento cobraba seis ducados y medio de plata por tonelada a los navíos marchantes de las Flotas y Galeones ${ }^{87}$, sin que al parecer la obligación se hiciera efectiva en la práctica.

Aquel mismo año de 1738 se acometió la limpieza del caño del Trocadero, a partir de un asiento firmado entre el rey y el hombre de negocios Agustín Ramírez

83. Iglesias Rodríguez, J. J.: «El Trocadero en la política atlántica...», art. cit.

84. AHMC, LAC, año 1738, cabildo de 15 de enero, fol. $19 \mathrm{v}$.

85. Idem, fol. 22.

86. Idem, fol. 25 .

87. AHMC, LAC, año 1738, cabildo de 15 de marzo, fols. 148-149v. 
Ortuño ${ }^{88}$. En virtud de esta contrata, Ramírez Ortuño se obligó a realizar esta tarea a su costa con un pontón y dos lanchas o, en caso necesario, con dos pontones y cuatro lanchas. La duración del contrato se fijó en doce años, al cabo de los cuales Ramírez Ortuño se obligaba a dejar el caño en el mejor estado posible para poder amarrar y carenar en él los navíos de la Carrera de Indias. El presidente de la Casa de Contratación, don Francisco de Varas y Valdés, había informado al gobierno de Felipe V de lo urgente que resultaban estos trabajos por la utilidad que depararían al comercio y a los propietarios de navíos, como también del riesgo cierto de que el caño se cegara y quedara inutilizado para el tráfico en el caso de que dichos trabajos no se llevaran a cabo. De las propuestas que se presentaron, la de Ramírez Ortuño era la más convincente. Ofreció una fianza de veinticinco mil ducados de plata y se obligó a que pondría el caño en disposición de recibir en su interior a los mayores navíos en las más cortas mareas, haciéndolo dragar de manera continua desde Fort-Luis hasta el sitio «que llaman del Pozo, o caño del Arillo, que cae en la parte de la villa de Puerto Real». Todo el fango que se extrajese se habría de depositar en los márgenes del caño, a una y otra banda, «que es donde se aseguran y afianzan las ondas para el amarradero de los navíos». El asentista nombraría y mantendría a su costa un guarda encargado de celar que no se arrojaran desde los navíos anclados en el caño lastres ni ninguna otra cosa que pudiese perjudicar la conservación y limpieza del mismo. El presidente y jueces asesores de la Casa de Contratación, por su parte, fijarían multas para los contraventores de esta disposición. Asimismo, se establecía en la contrata que si algún navío u otro tipo de embarcación fuese a pique en el caño, sería obligación de su dueño sacarla; pero, si estuviera en concurso por quiebra o no compareciera el propietario, entonces quedaría a cargo del asentista este trabajo, quedando a su beneficio el casco y todo cuanto contuviese ${ }^{89}$.

Ramírez Ortuño recibía a cambio de la obligación de mantener el caño limpio y expedito para la navegación diversas concesiones. En primer lugar, la facultad de construir almacenes de madera en la parte que tuviese por más conveniente para poder conservar los pertrechos de los pontones y demás cosas necesarias para la limpieza del caño, como ya se había ejecutado para los navíos de aviso del Consulado, sin que enfrente de tales almacenes pudiese anclar ningún navío, a fin de que no embarazase el tráfico ni la carena de los pontones. En segundo lugar, el contratista disfrutaría a la hora de construir los pontones de los mismos privilegios que gozaban los armadores de la Carrera de Indias, de modo que no sufriría

88. AHMC, LAC, año 1739, fols. 72-75. Copia de un Real Despacho (Aranjuez, 13 de junio de 1738) en razón del asiento de la limpieza del caño del Trocadero.

89. Ibidem. 
ningún impedimento para comprar y cortar madera en los parajes que estimase más oportunos, pagándola a su justo precio. Ramírez Ortuño quedaría también libre del pago de cualquier contribución en todo lo que fuese necesario para los pontones, para la limpieza del caño y para la fábrica de almacenes. También podría escoger libremente el lugar para establecer el astillero de los pontones, «sea en el Puerto de Santa María, Jerez, Puerto Real, Sanlúcar u otro cualquiera que eligiere en los contornos de Cádiz» ${ }^{90}$.

Sin embargo, las concesiones más ventajosas que Agustín Ramírez Ortuño obtuvo por el asiento de la limpieza del Trocadero fueron de tipo comercial. A través de ellas se comprueba las verdaderas intenciones del asentista y la importancia que el gobierno concedía al Trocadero como arsenal de la Carrera. Así, Ramírez Ortuño podría incorporar un navío de trescientas a cuatrocientas toneladas en calidad de patache en cada una de las Flotas y Galeones que se enviaran a Indias durante los doce años de duración del contrato, cargándolo por cuenta propia o a flete, en los mismos términos que se practicaba con los navíos de la Real Armada. Esta gracia comenzaría a disfrutarla en la siguiente Flota que se despacharía a Veracruz. Asimismo, en el caso de que no se despacharan flotas, podría enviar igualmente el patache referido siempre que fuesen navíos de registro por cuenta de particulares a Veracruz o Cartagena de Indias. Ramírez Ortuño, no obstante, habría de contribuir con ochenta pesos por cada flota o navíos que fuesen a Nueva España y con sesenta pesos por los que fuesen a Tierra Firme, además de los derechos que le correspondiesen en virtud de media anata y extranjería ${ }^{11}$.

La gestión que Ramírez Ortuño realizó del asiento para la limpieza del caño del Trocadero no fue satisfactoria. Entre 1740 y 1741 se siguieron autos judiciales por esta causa ${ }^{92}$. Ramírez Ortuño fue un personaje ambicioso y controvertido, protagonista por aquellos años de arriesgadas empresas que le llevaron a enfrentarse con el comercio gaditano ${ }^{93}$. Lo cierto es que en 1744 , cuando solo había transcurrido la mitad del plazo fijado en el asiento, el marqués de la Ensenada rescindió el contrato a instancias de la Casa de Contratación ${ }^{94}$. A partir de entonces, las labores de limpieza del caño del Trocadero entraron en un compás de espera. El

90. Ibidem.

91. Ibidem.

92. AGI, Escribanía, 1124C y 960.

93. Martínez Shaw, C.: «Un mercader gaditano del siglo xviII: Agustín Ramírez Ortuño», Archivo Hispalense, 196, 1981, pp. 29-41; «El asiento de 1741 y el abastecimiento de frutos a Nueva España», Moneda y Crédito, 161, 1982, pp. 21-35. Sobre Agustín Ramírez Ortuño, vid., también, Iglesias Rodríguez, J.-J.: Una ciudad mercantil en el siglo XVIII: El Puerto de Santa María. Sevilla, 1991, pp. 392-398.

94. Martínez Shaw, C.: «Un mercader...», art. cit., pp. 32-33.

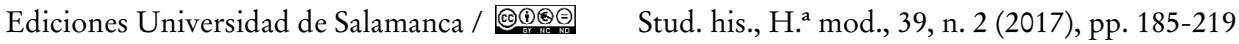


Consulado gaditano, necesitado de que el caño se mantuviera en buenas condiciones de navegación, reemprendió pasado un cierto tiempo la iniciativa, construyendo pontones a su costa y consiguiendo que se aprobara un reglamento para que los propietarios de navíos de la Carrera de Indias y los dueños de almacenes, casas y otras instalaciones levantadas a orillas del caño contribuyesen al mantenimiento del mismo. De esta forma, los barcos de la Carrera satisfarían dos pesos por cada tonelada de ropa y un peso por cada tonelada de frutos que transportasen, por cuya vía se estimaba que se recaudarían nueve mil pesos anuales para la limpieza del Trocadero. Además, el Seminario de San Telmo contribuiría con un peso y medio por cada tonelada que cargase en las flotas; con mil pesos el propio Consulado por los almacenes, dique y amarradero de navíos de aviso que mantenía en el caño; y con otros mil la Compañía de la Habana por el mismo concepto. Los particulares establecidos en el Trocadero también contribuirían a la limpieza del caño en diverso grado, a proporción de sus propiedades ${ }^{95}$.

Este reglamento quedó pronto desfasado, ya que en las décadas de 1750 y 1760 se produjo un notable crecimiento del número de particulares establecidos en el Trocadero, así como también un importante aumento de los almacenes e instalaciones del caño. En 1769 se actualizó, incluyendo a los nuevos propietarios, entre los que destacaban Francisco Tabernilla, Miguel de Soto, Jacinto de Barrios o el conde de Reparaz ${ }^{96}$. Los decretos de libre comercio de 1778 implicaron un cambio profundo en el sistema. Ahora los navíos del comercio americano podían partir de una amplia nómina de puertos peninsulares, además de Cádiz. Sin embargo, la necesidad de conservar en buenas condiciones el Trocadero subsistía para el comercio gaditano. Ello acarreó nuevamente la necesidad de modificar la reglamentación de contribuciones, en la que se incorporó también a los navíos extranjeros que entraban en el caño a descargar, cargar, carenar o repararse ${ }^{97}$. Los cambios producidos fueron aún mayores, en la medida que años antes, en 1764, concluyó la contrata entre el Consulado y la Real Hacienda para el mantenimiento de los navíos de aviso despachados a Indias, cuya base fue trasladada por el gobierno a La Coruña. Los almacenes del Consulado fueron cedidos entonces a la Real Hacienda para que esta guardase el azogue que enviaba a las colonias y las piezas de artillería de la Armada. Los navieros gaditanos intentaron también dar una solución definitiva a los continuos problemas que los depósitos de fango originaban en el Trocadero. En 1765 presentaron al presidente de la Casa de Contratación un proyecto para

95. AGI, Consulados, 1367, n. $^{\circ} 1$.

96. AGI, Consulados, 1367, reglamento de 1769.

97. Idem, reglamento de 1779. 
amurallar ambas orillas del caño mediante sólidos diques ${ }^{98}$, obra puesta bajo la responsabilidad de un activo miembro del Consulado, Francisco Guerra de la Vega $^{99}$. Sin embargo, esta solución tampoco fue definitiva. El Consulado invirtió gruesas sumas en las obras de amurallamiento, que a la larga resultaron inefectivas, ya que, a pesar de todo, el fango seguía acumulándose en el lecho del caño, obligando a realizar nuevas labores de dragado. En 1790, el Consulado llevaba gastados cerca de seiscientos mil pesos en el acondicionamiento del Trocadero, pero había recaudado solo algo más de la mitad de esa cantidad a través de las contribuciones destinadas a este fin. El caño era visto como un gran activo para el comercio, en la medida que, por sus dimensiones, podía acoger potencialmente a numerosos navíos y erigirse en una infraestructura fundamental en la logística de la Carrera de Indias. De ahí las cuantiosas inversiones que se realizaron con vistas a su conservación y mantenimiento. La realidad era, sin embargo, tozuda y las mareas seguían devolviendo a su fondo lo que tan trabajosamente se extraía de él. Una labor ímproba que la naturaleza de la Bahía gaditana se encargaba una y otra vez de frustrar.

Aún así, la elección hecha en 1717, que postró a Sevilla y que, por el contrario, proyectó a Cádiz hasta que esta ciudad se erigió en uno de los primeros puertos comerciales del mundo, fue aparentemente la correcta. El potencial portuario gaditano y su capacidad de adaptación a las nuevas exigencias de la navegación y de las dinámicas del comercio internacional quedaron de sobra demostrados, a pesar de todos los inconvenientes y dificultades que han sido señalados.

\section{CONClusiones}

A la vista de todo lo anteriormente expuesto, es preciso concluir que las infraestructuras portuarias urbanas de Cádiz resultaban insuficientes ante el reto que representaron el traslado de la cabecera de flotas a Indias en 1679 y el de la Casa de la Contratación en 1717. A pesar de las inmensas posibilidades que ofrecía la bahía gaditana, fue necesario acometer un amplio programa de construcción de muelles y de ordenación de los espacios portuarios de la ciudad para dar respuesta a los desafíos navales y mercantiles que la nueva situación comportó.

98. AGI, Consulados, 1367, n. $^{\circ} 1$.

99. Iglesias Rodríguez, J.-J.: «La burguesía atlántica gaditana del siglo Xviri: visiones del mundo y transformaciones de mentalidad. Francisco Guerra de la Vega, comerciante y naviero", en Iglesias Rodríguez, J. J. y García Bernal, J. (eds.): Andalucía en el mundo atlántico moderno. Agentes y escenarios. Madrid, 2016, pp. 355-388.

Ediciones Universidad de Salamanca / 뾰 Stud. his., H. ${ }^{a}$ mod., 39, n. 2 (2017), pp. 185-219 
Al mismo tiempo, la intensificación del tráfico naval que conllevaron estas novedades, que se unieron a la designación de Cádiz como departamento marítimo y a la consiguiente puesta en marcha del arsenal real de la Carraca, supuso también que se hiciera necesario vigilar el estado de navegabilidad de la Bahía, modificado por la ejecución de grandes obras hidráulicas, como el cerramiento alternativo de los ríos Guadalete y San Pedro, y por la propia dinámica del intenso tráfico comercial que registró en el siglo xviII. El estudio de los factores condicionantes de tipo portuario del comercio gaditano en dicho siglo ha sido sin embargo escasamente abordado por la historiografía especializada, que ha privilegiado el análisis de la organización y la dinámica del tráfico mercantil, así como el de su clase protagonista, la burguesía de negocios gaditana.

La necesidad añadida de contar con un arsenal naval de la Carrera de Indias para la carena e invernada de los navíos mercantes que la frecuentaban y para el almacenamiento de los efectos navales utilizados por estas embarcaciones planteó, por su parte, nuevos retos. Este arsenal se situó en el paraje que ofrecía más posibilidades para su establecimiento: el caño del Trocadero, canal natural en principio idóneo para asumir estas funciones, pero que sin embargo exigió la realización de continuas labores de limpieza y obras de adaptación que supusieron importantes inversiones y desembolsos para el Consulado gaditano de comerciantes.

La construcción y la conservación de infraestructuras portuarias en la Bahía de Cádiz, como objetivos de interés estratégico general, conocieron continuos procesos de negociación que implicaron a instancias diversas: la Corona, las autoridades de Marina, las de la Casa de la Contratación y el Consulado, los cónsules de las naciones extranjeras asentadas en Cádiz, los cabildos municipales de esta ciudad y de otras poblaciones de la Bahía y los diversos agentes particulares interesados, tales como asentistas, comerciantes y navieros. Esta realidad implica que el análisis de Cádiz como encrucijada atlántica en el siglo xviII deba integrar no solo elementos comerciales, navales y militares, sino también variables políticas de carácter dinámico y cambiante.

A lo largo del mencionado siglo se produjo un proceso de integración del complejo portuario de la Bahía en un esquema funcional claramente reconocible, formado por partes diversas complementarias entre sí. Dentro de este complejo, Cádiz representó, lógicamente, el núcleo principal, debido al carácter de la ciudad como emporio mercantil y financiero internacional y a la residencia en esta ciudad no solo de las más importantes compañías mercantiles, sino también de las instituciones rectoras del comercio colonial americano. Pero también hay que contar con el papel portuario jugado por la bahía interior (la conocida como Bahía de Puntales), con el de la Carraca como arsenal naval de la Corona, con el del Trocadero como arsenal y carenero de la Carrera de Indias y con los papeles 
JUAN JOSÉ IGLESIAS RODRÍGUEZ

LAS INFRAESTRUCTURAS PORTUARIAS DE LA BAHÍA DE CÁDIZ

ANTE EL RETO DEL MONOPOLIO AMERICANO

desempeñados por otras ciudades de la bahía gaditana, como es el caso de El Puerto de Santa María, ciudad mercantil complementaria de Cádiz, o Puerto Real, centro de una activa industria naval subsidiaria de la Marina y del comercio.

\section{Bibliografía}

Bustos Rodríguez, M.: Burguesía de negocios y capitalismo en Cádiz: los Colarte (16501750). Cádiz, 1991.

Bustos Rodríguez, M.: Cádiz en el sistema atlántico. La ciudad, sus comerciantes y la actividad mercantil (1650-1830). Madrid, 2005.

Crespo Solana, A.: «Cádiz y el comercio de Indias: Un paradigma del transnacionalismo económico y social (siglos XVI-XVII)», e-Spania [en línea], 25/octubre 2016. https://e-spania.revues.org/26016.

Chaunu, P.: Sevilla y América, siglos XVI y XVII. Sevilla. 1983.

Fernández Cano, V.: Las defensas de Cádiz en la Edad Moderna. Sevilla, 1973.

García-Baquero González, A.: Cádiz y el Atlántico (1717-1778). El comercio colonial español bajo el monopolio gaditano. Cádiz, 1988, 2 vols.

García-Baquero González, A.: Comercio y burguesía mercantil en el Cádiz de la Carrera de Indias. Cádiz, 1991.

GonzÁlez Beltrán, J. M. (ed.): El asalto anglo-holandés de 1702 a la Babia de Cádiz entre la política internacional y las repercusiones locales. El Puerto de Santa María, 2003.

igLesias Rodríguez, J.-J.: Una ciudad mercantil en el siglo XVIII: El Puerto de Santa María. Sevilla, 1991.

IgLesias RodRíguez, J.-J.: «El Trocadero en la política atlántica durante los siglos modernos», en Álvarez Santaló, L. C. (coord.): Estudios de Historia Moderna en homenaje al profesor Antonio García-Baquero. Sevilla, 2009, pp. 141-158.

IgLesias Rodríguez, J.-J.: «El 'canal prodigioso': el caño del Trocadero en el siglo XviII», Matagorda, 1, 2015, pp. 47-77.

IgLesias RodríGuez, J.-J.: «El complejo portuario gaditano en el siglo XviII», e-Spania. Revue interdisciplinaire d'études hispaniques médiévales et modernes, 25, oct. 2016 [en línea], https://e-spania.revues.org/25989.

Iglesias Rodríguez, J.-J.: «La burguesía atlántica gaditana del siglo xviII: visiones del mundo y transformaciones de mentalidad. Francisco Guerra de la Vega, comerciante y naviero», en Iglesias Rodríguez, J.-J. y García Bernal, J. (eds.): Andalucía en el mundo atlántico moderno. Agentes y escenarios. Madrid, 2016, pp. 355-388.

López Amador, J. J. y Pérez Fernández, E.: El Puerto Gaditano de Balbo. El Puerto de Santa María. Cádiz. Cádiz, 2013.

Márquez Carmona. L.: «El sistema portuario de la Bahía de Cádiz durante el siglo xviII», Revista de Historia de El Puerto, 36, 2006, pp. 11-47.

Márquez Carmona, L. y Alonso Villalobos, C.: «El sistema portuario de la bahía de Cádiz en época moderna a través de la cartografía histórica», en García Hurtado,

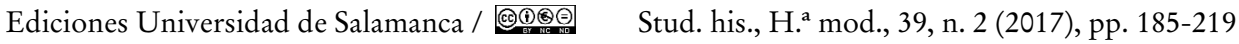


JUAN JOSÉ IGLESIAS RODRÍGUEZ

LAS INFRAESTRUCTURAS PORTUARIAS DE LA BAHÍA DE CÁDIZ

ANTE EL RETO DEL MONOPOLIO AMERICANO

M.-R. y Rey Castelao, O.: Fronteras de agua: las ciudades portuarias y su universo cultural (siglos XVI-XXI). Santiago de Compostela, 2016, pp. 181-195.

Márquez Carmona, L., Alonso Villalobos, C. y Benítez López, D.: «El patrimonio cultural marítimo de la Bahía de Cádiz según la visión de un hidrógrafo de Napoleón: El vicealmirante Rosily», Revista de Historia de El Puerto, 56, 2016, pp. 31-60.

Martínez Shaw, C.: «Un mercader gaditano del siglo xviri: Agustín Ramírez Ortuño», Archivo Hispalense, 196, 1981, pp. 29-41.

Martínez Shaw, C.: «El asiento de 1741 y el abastecimiento de frutos a Nueva España», Moneda y Crédito, 161, 1982, pp. 21-35.

Pérez Fernández Turégano, C.: «El Almirantazgo del infante don Felipe (1737-1748). Conflictos competenciales con la Secretaría de Estado y del Despacho de Marina», Anuario de Historia del Derecho Español, LXXIV, 2004, pp. 409-473.

Pérez Serrano, J. y Román Antequera, A.: «La salida marítima en el Marco del Jerez: transporte fluvial y ferroviario, ¿opuestos o complementarios?», Congreso de Historia Ferroviaria, 2009, [en línea], www.docutren.com/HistoriaFerroviaria/ PalmaMallorca2009/pdf/0207_Perez_Roman.pdf.

Quintero González, J.: El arsenal de la Carraca (1717-1736). Madrid, 2000.

Quintero González, J.: La Carraca: el primer arsenal ilustrado español (1717-1776). Madrid, 2005.

SAncho De Sopranis, H.: Historia del Puerto de Santa María desde su incorporación a los dominios cristianos en 1259 hasta el año mil ochocientos. Cádiz, 2007.

SAUPIN, G.: «Mondialisation et modification des hiérarchies des grands ports de commerce, mi XVIIe - mi xIxe siècle: une comparaison entre l'Espagne, la France et la Grande Bretagne», Nuevo Mundo. Mundos Nuevos [en línea], http://nuevomundo.revues. org/69920.

Torrejón Chaves, J.: «El área portuaria de la Bahía de Cádiz: tres mil años de puerto», en Puertos españoles en la Historia. Madrid, 1994, pp. 117-145.

Vallejo García Hevia, J. M.a: «Los navíos de aviso y los correos marítimos a Indias (1492-1898)», Ius fugit. Revista interdisciplinar de estudios histórico-jurídicos, 7, 1998, pp. 197-268.

Ediciones Universidad de Salamanca / @®@@ Stud. his., H. ${ }^{a}$ mod., 39, n. 2 (2017), pp. 185-219 
